\title{
Recent Advances in Enzymatic Fuel Cells: Experiments and Modeling
}

\section{Ivan Ivanov ${ }^{1}$, Tanja Vidaković-Koch ${ }^{2, *}$ and Kai Sundmacher ${ }^{1,2}$}

1 Max-Planck-Institute for Dynamics of Complex Technical Systems, Sandtorstrasse 1, D-39106 Magdeburg, Germany; E-Mails: ivanov@mpi-magdeburg.mpg.de (I.I.); sundmacher@mpi-magdeburg.mpg.de (K.S.)

2 Otto-von-Guericke University Magdeburg, Universitätsplatz 2, D-39106 Magdeburg, Germany

* Author to whom correspondence should be addressed; E-Mail: vidakovi@mpi-magdeburg.mpg.de; Tel.: +49-391-6110319; Fax: +49-391-6110553.

Received: 4 January 2010; in revised form: 23 February 2010 / Accepted: 3 March 2010 / Published: 21 April 2010

\begin{abstract}
Enzymatic fuel cells convert the chemical energy of biofuels into electrical energy. Unlike traditional fuel cell types, which are mainly based on metal catalysts, the enzymatic fuel cells employ enzymes as catalysts. This fuel cell type can be used as an implantable power source for a variety of medical devices used in modern medicine to administer drugs, treat ailments and monitor bodily functions. Some advantages in comparison to conventional fuel cells include a simple fuel cell design and lower cost of the main fuel cell components, however they suffer from severe kinetic limitations mainly due to inefficiency in electron transfer between the enzyme and the electrode surface. In this review article, the major research activities concerned with the enzymatic fuel cells (anode and cathode development, system design, modeling) by highlighting the current problems (low cell voltage, low current density, stability) will be presented.
\end{abstract}

Keywords: biofuel cell; enzymatic electrode; bioelectrocatalysis; modeling

\section{Introduction}

Enzymatic fuel cells are a type of fuel cells, which employ enzymes (biocatalysts) instead of conventional noble metal catalysts. The working principle is the same as in conventional fuel cells, namely fuel is oxidized at the anode side, and the electrons that are released by the oxidation reaction 
are driven through an outer electrical circuit, thus generating electric current. Finally, the electrons reach the cathode, where they combine with an oxidant (typically oxygen) and protons to a product (typically water). The working principle and main components of the conventional polymer electrolyte membrane (PEM) fuel cell and an enzymatic fuel cell are depicted in Figure 1.

Figure 1. Schematic presentation of conventional PEM fuel cell and enzymatic biofuel cell.

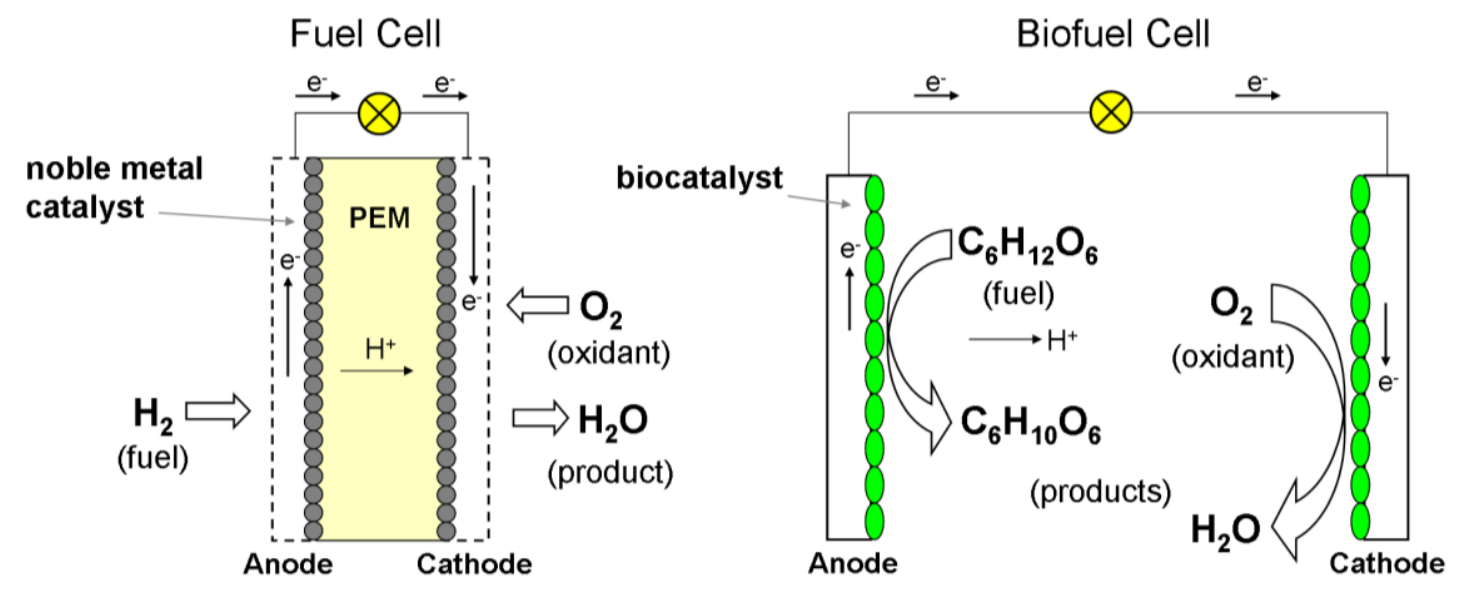

Utilization of biocatalysts provides several advantages over the conventional noble metal catalysts. Biocatalysts are inexpensive and their extended usage is expected to lower the cost of production, opposed to transition metal catalysts due to their limited availability. They are highly efficient systems exhibiting high turnover numbers, selectivity and activity under mild conditions (neutral $\mathrm{pH}$ and near-body temperature). The substrate specificity diminishes reactants cross-over, which theoretically enables a membraneless fuel cell design. In addition, biocatalysts allow the utilization of more complex fuels (as their natural substrates abundant in nature), opposed to the relatively poor chemistry of hydrogen and methanol as typical fuels for conventional fuel cells.

However the biocatalysts have some disadvantages compared to transition metal catalysts. In general, redox proteins tend to exhibit their superior catalytic properties exclusively in their natural environment or, in other words, nature did not evolve enzymes for bioelectrocatalytical applications. This is usually manifested by the difficulty in establishing electrical communication between the protein and the electrode surface and by the limited stability of the biocatalyst-electrode assembly. Another drawback of enzymes from a chemical engineering point of view is the lower volumetric catalyst density. Enzymes are large molecules, so the number of active sites per volume is usually lower compared to conventional metal electrodes.

The progress in biofuel cell research has often been reviewed in the literature. Minteer and coworkers, who are very active in the field, have summarized recent trends and accomplishments, stressing the use of three-dimensional structures and the commonly employed characterization techniques [1,2]. Emphasis on enzymes and their properties with respect to biofuel cell applications has been recently put by Kannan et al. [3] and Armstrong [4]. Summary of their own pioneering works has been made by Heller [5] and Willner [6,7]. The extensive reviews by Barton et al. [8] and Bullen et al. [9] are also worth noting. They provide a useful roadmap by discussing general aspects, 
fundamental definitions and classification in biofuel cell research. Common feature for previous reviews is that they cover not only whole biofuel cell assemblies but also single enzymatic electrodes with intended biofuel cell applications. Our goal is not to duplicate previous review efforts, but to provide a comprehensive overview of state-of-the-art enzymatic biofuel cells. We have limited our scope exclusively to whole fuel cell systems employing at least one enzymatic electrode and focused on the different reactants and electrode architectures for the anodic and cathodic reactions as well as on some modeling aspects in enzymatic fuel cells research. Unfortunately, due to the variety of experimental conditions, i.e., different fuel concentrations, a straightforward comparison in terms of performance characteristics is not possible. We have rather highlighted some of the accomplishments in biofuel cell development and discussed the recent trends in this research field.

\section{Enzymatic Fuel Cells in the Context of Biofuel Cells}

According to the traditional definition, enzymatic fuel cells are a type of biofuel cells, which utilize isolated enzymes [8]. If the biocatalysts are located inside living cells, the biofuel cells are referred to as microbial, although in a recent report [10] it was shown that not only bacteria but also human cells can be employed as catalysts in a fuel cell device. The use of single enzymes (or enzyme cascades) allows to have defined reaction pathways on the electrode surface and to overcome the limited output performance of microbial biofuel cells, which is considered to be due to mass transfer resistances across the cell membranes [8]. On the other side, enzymes still cannot compete with microbes in terms of long-term stability and fuel utilization (complete oxidation).

There are also examples in the literature, where an enzymatic electrode has been combined with a conventional catalyst electrode. Provided that an abiotical electrode usually exhibits higher stability, metal catalysts for the anodic reaction [11-17] and more often for the cathodic reaction [18-30] have been employed in order to complete the electrical circuit and to test the bioelectrodes under "fuel cell" conditions. The presence of one biocomponent (either anode or cathode) commonly allows the authors to refer to the studied systems as biofuel cells. Just recently, a fuel cell incorporating silicon nanoparticles for the electrooxidation of glucose and microperoxidase-11 for the reduction of hydrogen peroxide has been stated as a "hybrid cell" [31].

\section{Future Applications of Biofuel Cells}

The variety of intended enzymatic biofuel cell applications suggested in the literature tends to be roughly broken into two classes: implantable power and general power. In general, the utilization of such systems as possible power generating devices is disputable since state-of-the-art enzymatic fuel cells cannot compete with the conventional energy generators in terms of power output and stability. Nevertheless, in the context of electrochemical power, worth noting is the prototype bio battery introduced by Sony® in 2007, which is based on the enzymatic biofuel cell configuration reported by Sakai et al. [32].

The unique properties of biocatalysts suggest the employment of biofuel cells in uncommon, niche applications and the most evident are for implantable power [8,9]. The recent advances in the development of implantable electrically operated devices raised the need of new power sources that would fit their specific requirements. The miniaturization of biomedical devices demands 
miniaturization of their power sources, since the size of the electrical device is usually dominated by the size of the battery [33]. Theoretically there are a number of biomedical accessories that would take advantage of a small implantable power source such as the biofuel cell, including the cardiac pacemaker, neurostimulators, hearing and vision devices, drug pumps, glucose sensors, bladder-control valves, etc. [8,9]. However, according to Adam Heller, one of the pioneers in the field, biofuel cells could not compete with conventional Li-based batteries as power supplies for a pacemaker (due to short operational life) or neurostimulators (due to limited power output) [5]. He proposes particular applications in autonomous and disposable sensor-transmitter systems for monitoring bodily functions [5] or the integration in medical feedback systems for drug-delivery, i.e., for diabetes monitoring and control [34]. After all, in spite of the large amount of conducted research, state-of-the-art biofuel cells are almost exclusively in a proof-of-concept stage, and once the technology is mature, new potential applications could be identified.

\section{Fuels, Oxidants and Biocatalysts Used in Enzymatic Fuel Cells}

\subsection{Fuels}

The nature of employed catalysts in enzymatic fuel cells allows the utilization of numerous fuels including variety of sugars and low aliphatic alcohols. The main fuels and the respective enzymes used for their bioelectrocatalytic oxidation are listed in Table 1 below.

The most common and intuitive fuel for enzymatic biofuel cells is glucose due to its high abundance in nature and essential role in human metabolism. Glucose is an important metabolic intermediate and a source of energy for a variety of living organisms. It is an aldohexose carbohydrate and from the two stereoisomers only the dextrorotatory (D-glucose) is biologically active. Glucose is involved in the glycolysis metabolic pathway, where it is oxidized to pyruvate, which further enters the citric acid cycle. Eventually, after series of chemical transformations with a release of energy, glucose is broken down to $\mathrm{CO}_{2}$ and water. Other sugars that have been employed as fuels are fructose, which is a structural isomer of glucose as well as some disaccharides as lactose and cellobiose. The application of the latter two was governed rather by the high affinity of the enzyme cellobiose dehydrogenase for these substrates.

Other fuels that have been used in enzymatic fuel cells are aliphatic alcohols such as methanol, ethanol and glycerol. Methanol has been already identified as one of the best fuels in conventional direct fuel cells, which can be used as power supplies for portable applications. Ethanol has drawn more attention as a biofuel that can be produced by fermentation of biomass and is already commercially available for combustion engines. Glycerol is also an attractive fuel due to its high energy density, low vapor pressure and low toxicity opposed to the latter alcohols. All three alcohols can be regarded as renewable fuels that can be produced from biomass and their utilization in enzymatic fuel cells could offer new types of small-scale power generators. Other fuels that have been employed are pyruvate, which use was directed by its abundance and importance as a metabolic intermediate and hydrogen as a non-carbon containing fuel, which is known as a prominent substrate for conventional fuel cells. 
Table 1. Fuels and enzymes used in enzymatic biofuel cells.

\begin{tabular}{|c|c|c|c|c|}
\hline Fuel & Enzyme & Co-factor & Half-Cell Reaction & $\begin{array}{l}\text { Natural } \\
\text { Acceptor }\end{array}$ \\
\hline \multirow{4}{*}{ glucose } & glucose oxidase, EC 1.1.3.4 & FAD & glucose $\rightarrow$ glucono-1,5-lactone $+2 \mathrm{H}^{+}+2 \mathrm{e}^{-}$ & $\mathrm{O}_{2}$ \\
\hline & glucose dehydrogenase, EC 1.1.1.47 & NAD & see above & NAD \\
\hline & glucose dehydrogenase, EC 1.1.5.2 & PQQ & see above & quinone \\
\hline & cellobiose dehydrogenase, EC 1.1.99.18 & FAD, heme & see above & acceptor \\
\hline fructose & fructose dehydrogenase, EC 1.1.99.11 & FAD, heme & fructose $\rightarrow 5$-dehydrofructose $+2 \mathrm{H}^{+}+2 \mathrm{e}^{-}$ & acceptor \\
\hline cellobiose & cellobiose dehydrogenase, EC 1.1.99.18 & FAD, heme & cellobiose $\rightarrow$ cellobiono-1,5-lactone $+2 \mathrm{H}^{+}+2 \mathrm{e}^{-}$ & acceptor \\
\hline lactose & cellobiose dehydrogenase, EC 1.1.99.18 & FAD, heme & $\begin{array}{c}\text { lactose } \rightarrow \text { 4-O-(galactopyranosyl)-glucono-1,5- } \\
\text { lactone }+2 \mathrm{H}^{+}+2 \mathrm{e}^{-}\end{array}$ & acceptor \\
\hline \multirow{4}{*}{ methanol } & alcohol dehydrogenase*, EC 1.1.1.1 & NAD & alcohol $\rightarrow$ aldehyde $+2 \mathrm{H}^{+}+2 \mathrm{e}^{-}$ & NAD \\
\hline & aldehyde dehydrogenase*, EC 1.2.1.5 & NAD & aldehyde $+\mathrm{H}_{2} \mathrm{O} \rightarrow$ acid $+2 \mathrm{H}^{+}+2 \mathrm{e}^{-}$ & NAD \\
\hline & formate dehydrogenase*, EC 1.2.1.2 & NAD & formate $\rightarrow \mathrm{CO}_{2}+2 \mathrm{H}^{+}+2 \mathrm{e}^{-}$ & NAD \\
\hline & alcohol dehydrogenase, EC 1.1.99.8 & PQQ, heme & alcohol $\rightarrow$ aldehyde $+2 \mathrm{H}^{+}+2 \mathrm{e}^{-}$ & acceptor \\
\hline \multirow{3}{*}{ ethanol } & alcohol dehydrogenase*, EC 1.1.1.1 & NAD & see above & see above \\
\hline & aldehyde dehydrogenase*, EC 1.2.1.5 & NAD & see above & see above \\
\hline & alcohol dehydrogenase, EC 1.1.99.8 & PQQ, heme & see above & see above \\
\hline \multirow{3}{*}{ glycerol } & alcohol dehydrogenase*, - & PQQ, heme & alcohol $\rightarrow$ aldehyde $+2 \mathrm{H}^{+}+2 \mathrm{e}^{-}$ & - \\
\hline & aldehyde dehydrogenase*, - & PQQ, heme & aldehyde $+\mathrm{H}_{2} \mathrm{O} \rightarrow$ acid $++2 \mathrm{H}^{+}+2 \mathrm{e}^{-}$ & - \\
\hline & oxalate oxidase*, EC 1.2.3.4 & FAD, Mn & oxalate $\rightarrow 2 \mathrm{CO}_{2}+2 \mathrm{H}^{+}+2 \mathrm{e}^{-}$ & $\mathrm{O}_{2}$ \\
\hline pyruvate & pyruvate dehydrogenase*, EC 1.2.4.1 & NAD & pyruvate $+\mathrm{CoA} \rightarrow$ acetylCoA $+2 \mathrm{H}^{+}+2 \mathrm{e}^{-}$ & NAD \\
\hline hydrogen & membrane-bound hydrogenase, - & - & $\mathrm{H}_{2} \rightarrow 2 \mathrm{H}^{+}+2 \mathrm{e}^{-}$ & - \\
\hline
\end{tabular}

*enzymes taking part in complete fuel oxidation

The commonly reported anodic systems use only one enzyme, which catalyzes partial oxidation of the fuel. The redox process is associated with the breakage of one chemical bond, which limits the number of electrons that can be gained from the anodic reaction to two. In this context, worth noting is the employment of enzyme cascades, which allow better utilization of the chemical energy of the fuel and can be used for complete oxidation to $\mathrm{CO}_{2}$. The cascade of bioelectrochemical transformations on the electrode surface allows summation of the electrons from every single reaction and thus increases the total current density delivered by the fuel cell. Such enzyme cascades have been presented in the case of methanol, ethanol, glycerol and pyruvate and examples will be discussed further in the text.

\subsection{Oxidants}

The most widely employed oxidant in enzymatic biofuel cells is oxygen and there are only few reports of other compounds. The respective half-cell reactions and enzymes used for the bioelectrochemical reduction are listed in Table 2 below.

Oxygen is the typical oxidant in conventional fuel cells, where it is used in the form of pure gas or air. On the other side, molecular dioxygen is essential for the respiration in all aerobic organisms and its ubiquity in humans directs its application as an oxidant in potentially implantable fuel cell systems. In the case of enzymatic fuel cells it is usually used dissolved in aqueous electrolyte whereby its low water solubility raises additional mass transport problems but there are also reports of enzymatic fuel 
cells utilizing gas phase oxygen. The four-electron reduction to water catalyzed by the respective enzymes represents the cathodic half-cell reaction $[35,36]$.

Table 2. Oxidants and enzymes used in enzymatic biofuel cells.

\begin{tabular}{|c|c|c|c|}
\hline Oxidant & Enzyme & $\begin{array}{c}\text { Metal/ } \\
\text { Co-factor }\end{array}$ & Half-cell Reaction \\
\hline \multirow{4}{*}{ oxygen } & laccase, EC 1.10.3.2 & $\mathrm{Cu}$ & $\mathrm{O}_{2}+4 \mathrm{H}^{+}+4 \mathrm{e}^{-} \rightarrow 2 \mathrm{H}_{2} \mathrm{O}$ \\
\hline & bilirubin oxidase, EC 1.3.3.5 & $\mathrm{Cu}$ & see above \\
\hline & cytochrome oxidase, EC 1.9.3.1 & $\mathrm{Cu}, \mathrm{Fe} /$ heme & see above \\
\hline & cytochrome c, - & $\mathrm{Fe} /$ heme & - \\
\hline \multirow{3}{*}{$\begin{array}{l}\text { hydrogen } \\
\text { peroxide }\end{array}$} & microperoxidase-11, - & Fe / heme & $\mathrm{H}_{2} \mathrm{O}_{2}+2 \mathrm{H}^{+}+2 \mathrm{e}^{-} \rightarrow 2 \mathrm{H}_{2} \mathrm{O}$ \\
\hline & horseradish peroxidase, EC 1.11.1.7 & $\mathrm{Fe} /$ heme & see above \\
\hline & (glucose, GOx) microperoxidase- $8,-$ & $\mathrm{Fe} /$ heme & see above \\
\hline $\begin{array}{l}\text { cumene } \\
\text { peroxide }\end{array}$ & microperoxidase-11, - & $\mathrm{Fe} /$ heme & $\mathrm{C}_{9} \mathrm{H}_{12} \mathrm{O}_{2}+2 \mathrm{H}^{+}+2 \mathrm{e}^{-} \rightarrow \mathrm{C}_{9} \mathrm{H}_{12} \mathrm{O}+\mathrm{H}_{2} \mathrm{O}$ \\
\hline
\end{tabular}

Other oxidant that has been rarely employed is hydrogen peroxide. The highly reactive oxygen species has strong oxidizing properties and can be harmful to biological components such as enzymes. This governs its utilization in two-compartment systems [37], where major part of the cost is due to the membrane. There is also one report in the literature, where cumene hydroperoxide has been used as an oxidant in a biofuel cell based on two immiscible solvents [38].

\subsection{Enzymes}

\subsubsection{Enzymes for the anodic reaction.}

From the enzymes that are capable of glucose oxidation, glucose oxidase (EC 1.1.3.4, GOx) is the most widely employed in the area of biosensors and biofuel cells. GOx is a dimer, composed of two identical subunits with a mean total molecular mass of $160 \mathrm{kDa}$, an average diameter of $8 \mathrm{~nm}$ and isoelectric point of about 4.2 [39]. The redox co-factor responsible for the catalytic function of GOx is flavin adenine dinucleotide (FAD), which contains a riboflavin moiety. GOx catalyzes the conversion of glucose to gluconolactone, which spontaneously hydrolyzes to gluconic acid. The natural electron acceptor for GOx is oxygen, which in the course of the natural reaction is reduced to hydrogen peroxide [39]. As discussed in the previous section, the generation of hydrogen peroxide in the vicinity of the electrode should be avoided. Moreover, in a membraneless configuration the natural acceptor oxygen would compete for the released electrons with the electrode and thus will decrease the anodic current density.

Another enzyme that has been widely used in biofuel cell applications is glucose dehydrogenase (EC 1.1.1.47, GDH). It has some advantages over GOx because its natural electron acceptor is not oxygen, but is expected to find limited application in implantable enzymatic biofuel cells since it requires a soluble co-factor: nicotinamide adenine dinucleotide $\left(\mathrm{NADH} / \mathrm{NAD}^{+}\right)$. A promising enzyme, recently introduced by Gorton and collaborators for biofuel cell applications is cellobiose dehydrogenase (EC 1.1.99.18, CDH) [18,40]. Its natural substrate is cellobiose but CDH isolated from 
ascomycete fungi can also oxidize other disaccharides as lactose as well as variety of monosaccharides including glucose. The enzyme is a monomer containing a flavin and a heme domain. Other enzymes from the family of dehydrogenases that have been used in enzymatic biofuel cells are PQQ-dependent GDH (EC 1.1.5.2) [41] and fructose dehydrogenase (EC 1.1.99.11, FDH) [42,43] for oxidation of glucose and fructose respectively.

Different dehydrogenases have been employed for the oxidation of alcohols. Worth noting here are the enzyme cascades that allow full oxidation of the substrate. For instance, a sequence of NAD-dependent alcohol dehydrogenase (EC 1.1.1.1, ADH), aldehyde dehydrogenase (EC 1.2.1.5) and formate dehydrogenase ( $\mathrm{EC}$ 1.2.1.2) has been used for oxidation of methanol to $\mathrm{CO}_{2}$ [30]. The first two enzymes have been used for catalytic oxidation of ethanol to acetate, which has further been converted to acetyl co-enzyme A (acetyl-CoA) and subjected to a series of enzymes from the citric acid cycle [44]. Similar approach has been used in the case of pyruvate, which was converted to acetyl-CoA by pyruvate dehydrogenase (EC 1.2.4.1, PDH) and entered the citric acid cycle as in the previous case [45]. Other, PQQ-dependent dehydrogenases have been used for partial oxidation of ethanol [46] and glucose [41] as well as for full oxidation of glycerol together with oxalate oxidase (EC 1.2.3.4, OOx) [47]. Hydrogen oxidation has been achieved by employing membrane-bound hydrogenase $(\mathrm{MBH})$, which contains a Ni-Fe catalytic center and exhibits high tolerance to oxygen and carbon monoxide [48].

\subsubsection{Enzymes for the cathodic reaction.}

The typical enzymes used for oxygen reduction are plant and fungal laccases (EC 1.10.3.2) and bilirubin oxidase (EC 1.3.3.5, BOD). These are multi-copper oxidases that can oxidize a variety of substrates, and possess four metal ions classified into three types: T1, T2, and T3. The T1 site is known to bind the organic substrate and the T2/T3 cluster catalyzes the four-electron reduction of oxygen to water [35,36]. Laccases usually exhibit activity at slightly acidic conditions and are commonly employed at $\mathrm{pH} 5$, while BOD has activity in more alkaline media, which allows its utilization at neutral $\mathrm{pH}$. Another enzyme system used for oxygen reduction is cytochrome oxidase (EC 1.9.3.1, $\mathrm{COx}$ ) and cytochrome c, both containing heme as the catalytic center [49]. From the enzymes capable of hydrogen peroxide reduction microperoxidase-11 (MP-11) [37] and horseradish peroxidase (EC 1.11.1.7, HRP) [50] have been employed in biofuel cell. MP-11 is obtained by trypsic digestion of cytochrome $\mathrm{c}$ and consists of eleven amino acids and a covalently linked heme site, which represent the active site microenvironment of the native protein. MP-11 has been also used for the reduction of cumene peroxide, which was previously discussed [38]. Another microperoxidase, MP-8 has been used as a cathodic enzyme, catalyzing the reduction of hydrogen peroxide, generated by GOx [51]. 


\section{Typical Enzymatic Electrode Assemblies}

\subsection{Electron transfer as a factor determining the electrode architecture}

Before starting to discuss the existing examples of enzymatic electrodes employed in enzymatic fuel cells, we would like to address shortly the principal routes of achieving electron transfer since this determines to a great extent the electrode configuration. As mentioned above, a key issue in the development of enzymatic electrodes for biofuel cell applications is the efficient electrical communication between the enzyme and the electrode. If an enzyme is capable of transferring (rendering or receiving) electrons to the electrode, the process is termed Direct Electron Transfer (DET). Less than 100 from over 1000 redox enzymes are known to feature DET [52]. In general, enzymes that tend to exhibit DET possess spatially exposed redox relay located near the protein periphery.

In most of the cases, however, the redox unit is deeply buried into the protein structure and isolated with a thick carbohydrate shell. In order to overcome the kinetic barrier for electron transfer, a redox active species called mediator can be introduced to the bioelectrocatalytic system. It is used to shuttle electrons between the enzyme and the electrode and the process is referred to as Mediated Electron Transfer (MET). The basic electron transfer principles in the context of biosensors, applicable also to enzymatic biofuel cells, have been reviewed by Schuhmann et al. [53] and the main types of mediators used in biofuel cells research are summarized in a recent review [1].

Mediators tend to be very helpful for achieving electrical communication but the increased complexity of the system due to the introduction of additional components raises further problems. Apart from the intrinsic properties of the mediator (stability, toxicity), additional issues associated with mediator diffusion or leaching have to be tackled.

There is a huge variety of immobilization strategies for both enzymes and mediators that include simple physical adsorption, covalent attachment, cross-linking and entrapment in polymeric gels. Quite often the immobilization approach is a combination of these. In general, monolayer configurations tend to be displaced by multilayers or other three-dimensional (3D) structures in order to increase the current output. 3D-structures can also provide suitable immobilization matrices for the enzymes and thus retain for longer time their activity. Provided that efficient electrical communication is achieved, essential problem that could possibly arise is the limited mass transport of the fuel. Compared to conventional fuel cell electrodes, the enzymatic electrodes exhibit higher complexity and the immobilization procedures are usually associated with complicated chemistry. Some of the typical enzymatic electrode architectures are given in Figure 2.

We have classified the enzymatic electrodes present in the literature in the following three groups: assemblies without electron transfer mediator utilizing nanostructured materials as immobilization matrix (Figure 2A), assemblies involving immobilized mediator (Figure 2B) and assemblies with mediator attached to a polymer backbone (Figure 2C) and the respective examples further in the text are presented according to this classification. 
Figure 2. Schematic presentation of typical enzymatic electrode immobilization procedures.

(A) Architecture based on nanostructured materials without electron transfer mediator.

(B) Architecture based on enzymes and mediators entrapped in a three-dimensional matrix.

(C) Architecture based on mediators attached to a polymer backbone.

A)

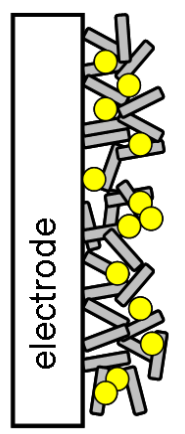

B)

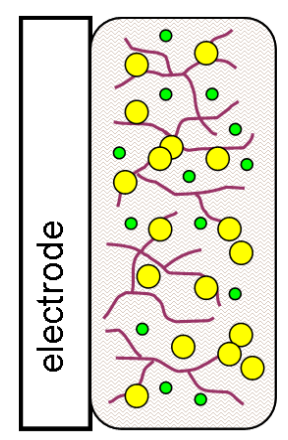

C)

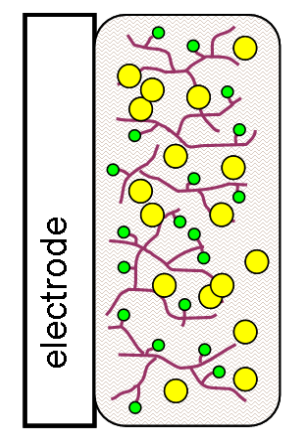

enzyme

$0^{\circ}$ mediator

immobilization

matrix

(e.g. polymer)

Wh nanomaterial

(e.g. CNT's)

\subsection{Configurations without electron transfer mediator}

Enzymatic electrode configurations without electron transfer mediator are usually realized with the help of carbon nanostructured materials [42,43,54,55] (see Figure 2A) or less often by covalent attachment of the enzyme on self-assembled monolayer modified surface [49]. In this ways different enzymes like GOx [54,55], FDH [42,43], CDH [18], laccase [12,15,43,56-58], BOD [35,42,59,60] and MP-8 [51] have been immobilized.

For instance, Dong and co-workers have used a viscous gel comprising carbon nanotubes (CNTs) and ionic liquid (1-butyl-3-methylimidazolium hexafluorophosphate, IL) as an immobilization matrix for GOx [61]. In other papers GOx was immobilized on carboxylated single-walled carbon nanotubes (SWCNT's) deposited by two different methods on a porous silicon substrate [55] or in a CNTs-hydroxyapatite composite [54]. SWCNT's were employed also for the immobilization of $\mathrm{CDH}$ [18].

Nanostructured materials were also used as immobilization matrix for FDH. In one of the configurations FDH was adsorbed in a cellulose-MWCNT's matrix applied with the help of a room temperature ionic liquid (RTIL), which was used to dissolve the cellulose [42]. Another nanostructured immobilization matrix was reported by Kano et al., where FDH was adsorbed on Ketjen Black-modified carbon paper [43]. In some electrode configurations enzymes were adsorbed on graphite, like CDH from Dichomera Saubinetii [40], MBH [48] or PQQ-dependent ADH (EC 1.1.99.8) [51].

Similar as in the case of anodic enzymes, immobilization procedures involving carbon nanostructured materials have been applied in the case of cathodic enzymes as well. BOD has been adsorbed on SWCNT's in the presence of bovine serum albumin (BSA) and glutaraldehyde (GA) as a cross-linker [59,62] or in the cellulose-MWCNT's matrix, which was mentioned above [42]. There are also reports of biocathodes obtained by immobilization of BOD on Ketjen Black nanoparticles [43,60]. Similar to BOD, laccases adsorbed in a carbon aerogel [43] or different CNT's-based matrices [12,56-58] have been reported.

Biocathodes for hydrogen peroxide reduction have been constructed also after adsorption of MP-8 [51] or HRP [50] on graphite. Worth noting are also the efforts of covalent attachment of cathodic enzymes, as in the case of MP-11 on a gold surface functionalized with a cystamine 
monolayer $[37,38]$ or $\mathrm{COx}$ and cytochrome $\mathrm{c}$, which was tethered via site-specific coupling through a maleimide monolayer [49].

\subsection{Configurations based on diffusional and immobilized mediators}

\subsubsection{Typical mediators employed in enzymatic fuel cells.}

The enzymatic electrode configurations without mediator are still outnumbered by mediator based configurations. The mediators which are commonly used in enzymatic fuel cells can be divided into two groups: free diffusive and immobilized mediators. The mediators are usually enzyme specific. An overview of typically used mediators for GOx and their formal redox potentials are disclosed in Table 3. It should be noted that the formal redox potential of the mediators varies with conditions ( $\mathrm{pH}$, soluble or immobilized, etc.) moreover several redox processes can be associated with a given compound. The potential values presented in the table are based on the respective references and should be regarded not as absolute but rather as benchmark values.

Table 3. Typical mediators for GOx-based glucose oxidation.

\begin{tabular}{lcccc}
\hline Mediator & $\begin{array}{c}\text { Redox Potential, } \\
\text { Recalculated Redox } \\
\text { Potential, V vs. SHE }\end{array}$ & pH & Reference \\
\hline ferrocene monocarboxylic acid & $\sim 0.34_{\mathrm{Ag} / \mathrm{AgCl}}$ & $\sim 0.54$ & 7 & {$[58]$} \\
$p$-benzoquinone & $\sim 0.02_{\mathrm{SCE}}$ & $\sim 0.26$ & 7 & {$[22]$} \\
phenazine methosufate & $0.08_{\mathrm{SCE}}$ & 0.32 & 6 & {$[63]$} \\
pyrroloquinoline quinone & $-0.13_{\mathrm{SCE}}$ & 0.11 & 7 & {$[37]$} \\
8-hydroxyquinoline-5-sulfonic acid & $0.065_{\mathrm{SCE}}$ & 0.305 & 5 & {$[64]$} \\
tetrathiafulvalene & $0.222_{\mathrm{Ag} / \mathrm{AgCl}}$ & 0.419 & 7 & {$[65]$} \\
\hline
\end{tabular}

$* \mathrm{~V} v s . \mathrm{Ag} / \mathrm{AgCl}=\mathrm{V}$ vs. $\mathrm{SHE}-0.197 ; \mathrm{V}$ vs. $\mathrm{SCE}=\mathrm{V}$ vs. $\mathrm{SHE}-0.24$

When GDH is employed for glucose oxidation, the regeneration of NADH on electrode surfaces usually takes place at high overpotentials, which necessitates the use of mediators as in the case of GOx. The most common mediators are presented in Table 4 and details of the electrode architectures are given further in the text.

Table 4. Typical mediators for GDH-based glucose oxidation.

\begin{tabular}{lcccc}
\hline Mediator & $\begin{array}{c}\text { Redox Potential, } \\
\text { V }\end{array}$ & $\begin{array}{c}\text { Recalculated Redox } \\
\text { Potential, V vs. SHE }\end{array}$ & pH & Reference \\
\hline poly(methylene blue) & $-0.10_{\mathrm{Ag} / \mathrm{AgCl}}$ & 0.1 & 6 & {$[66]$} \\
poly(brilliant cresyl blue) & $-0.11_{\mathrm{Ag} / \mathrm{AgCl}}$ & 0.09 & 7 & {$[62]$} \\
methylene green* & $-0.20 /-0.05_{\mathrm{Ag} / \mathrm{AgCl}}$ & $0 / 0.15$ & 6 & {$[56]$} \\
Meldola blue & - & - & - & {$[67]$} \\
Nile blue & $-0.35_{\mathrm{Ag} / \mathrm{AgCl}}$ & -0.15 & 7 & {$[68]$} \\
Thionine & - & - & - & {$[57]$} \\
\hline
\end{tabular}

*methylene green exhibits two redox pairs 
Enzymes which catalyze oxidation of other organic fuels (Table 1) have been also employed in mediator based enzymatic electrode configurations. An overview of typically used mediators in these systems is listed in Table 5 and the respective electrode assemblies are discussed further throughout the text.

In the case of oxygen reduction systems the most notable example of a mediator is 2,2'-azino-bis(3-ethylbenzthiazoline-6-sulfonic acid) (ABTS). ABTS is the most widely exploited mediator both for laccase [17] and BOD [11]. It has a redox potential of about $0.49 \mathrm{~V}$ versus $\mathrm{Ag} / \mathrm{AgCl}$ (0.69 V vs. SHE) at pH 7 [65], which is close to the redox potentials of multi-copper oxidases. Other mediators that have been employed are $\mathrm{Ru}(\mathrm{bpy})_{3}{ }^{2+/ 3+}[69]$ and potassium ferricyanide [32] both for the electrical coupling of BOD.

Table 5. Typical mediators for other fuels oxidation.

\begin{tabular}{cccccc}
\hline \multirow{2}{*}{ Fuel } & Mediator & $\begin{array}{c}\text { Redox } \\
\text { Potential, V }\end{array}$ & $\begin{array}{c}\text { Recalculated Redox } \\
\text { Potential, V vs. SHE }\end{array}$ & pH & Reference \\
\hline \multirow{2}{*}{ methanol } & $\begin{array}{c}\text { benzylviologen } \\
\text { tetramethyl- } p-\end{array}$ & $-0.55_{\mathrm{SCE}}$ & -0.31 & 7.5 & {$[30]$} \\
& $\begin{array}{c}\text { phenylenediamine } \\
\text { Nile blue }\end{array}$ & $-0.055 / 0.037 \mathrm{SCE}$ & $0.185 / 0.277$ & $7 / 10$ & {$[24]$} \\
ethanol & $-0.355_{\mathrm{Ag} / \mathrm{AgCl}}$ & -0.15 & 7 & {$[68]$} \\
glycerol & poly(methylene green $)$ & - & - & - & {$[44]$} \\
pyruvate & poly(methylene green) & - & - & - & {$[23]$} \\
\hline
\end{tabular}

\subsubsection{Architectures with diffusional mediators.}

Biofuel cells involving diffusional mediators are not expected to have any practical application as implantable devices and such studies usually address a novel enzyme immobilization matrix. For instance, Dong et al. have constructed biofuel cells with GOx entrapped in a CNT's-chitosan suspension [70] or in a CNT's-IL gel [71] and used ferrocene monocarboxylic acid (FMCA) as a mediator. Soluble FMCA was used also in biofuel cells based on MWCNT's mixed with GOx and a lipid [58] or glutaraldehyde-functionalized chitosan [72]. Benzoquinone was adopted as a mediator for GOx covalently attached through carbodiimide coupling to electropolymerized blend of 3-methylthiophene and thiophene-3-acetic acid [22]. Similar approach was also used for other fuels as in the case of methanol oxidation by PQQ-dependent ADH mixed with graphite paste in the presence of soluble $N, N, N^{\prime}, N^{\prime}$-tetramethyl-p-phenylenediamine (TMPD) [24]. The utilization of diffusional mediator is common also for studies on microfluidic biofuel cells, which are usually focused not on the electrode performance but rather on mass transport and design issues, i.e., a study on oxygen limitations in a microfluidic biofuel cell comprising soluble GOx and phenazine methosulphate [63]. 


\subsubsection{Architectures with immobilized mediators.}

More common in the area of biofuel cells is the application of immobilized mediator. Numerous strategies for immobilization of enzymes and mediators on the electrode surface have been reported in the literature $[20,32,57,59,62,65,67,73-76]$. In this section we concentrate on those procedures which use three-dimensional matrices like polymers, lipids and CNT's or combination of these (Figure 2B) to incorporate enzyme and mediators since these configurations are more practically relevant.

Tingry and coworkers employed 8-hydroxyquinoline-5-sulfonic acid (HQS) and ABTS as mediators for glucose oxidation and oxygen reduction, respectively $[64,73,76]$. The mediators were entrapped together with GOx and laccase or BOD on carbon tube electrodes and polypyrrole layer was electropolymerized over the respective anode and cathode assemblies. It was shown that the electrode stability increased if the enzyme was covalently grafted to a poly(aminopropylpyrrole) film and subsequently cross-linked with poly(ethylene glycol) diglycidyl ether (PEGDGE) [73]. HQS and ABTS were also co-entrapped with GOx and laccase in polypyrrole nanowires, grown on anodized aluminum oxide template [74].

Another interesting matrix for enzyme immobilization involving liquid-crystalline cubic phase, which resembles the natural environment of membrane proteins, was introduced by Bilewicz et al. [65]. The cubic phase was prepared by mixing monoolein (1-oleoyl-rac-glycerol) with enzymes and different mediators, including tetrathiafulvalene (TTF) and ABTS. The same mediators were also used in electrode architecture together with MWCNT's and a polyion complex formed by poly-L-lysine (PLL) and poly(sodium 4-styrenesulfonate) (PSS) [75].

A charge transfer complex (CTC), formed by TTF and tetracyanoquinodimethane (TCNQ), which was grown on polypyrrole surface and covered with protective gelatin layer was employed by our group as a glucose oxidation anode [77]. Another matrix for immobilization of GOx was formed by gelatin, MWCNT's and ferrocene [78].

Similar approaches have been used for construction of mediator based systems employing GDH as the biocatalyst. For instance, Kano and co-workers immobilized 2-methyl-1,4-naphthoquinone (Vitamin $\mathrm{K}_{3}, \mathrm{VK}_{3}$ ) and potassium ferricyanide as anodic and cathodic mediators, respectively, in a polyion complex matrix formed by polyacrylic acid and PLL [32]. Mao and co-workers reported several immobilization strategies utilizing CNT's and different azine dye-based mediators for the regeneration of the NADH co-factor, including polymethylene blue (polyMB) [59,66] and poly(brilliant cresyl blue) [62], which were electropolymerized over the CNT's. Glucose-based biofuel cells based on CNT's were constructed also with other azine-based mediators such as Meldola blue [67] and Nile blue [68].

Worth noting is also the Nafion-based immobilization matrix introduced by Minteer and co-workers, wherein modification of the polymer with quaternary ammonium salts provided suitable environment for the biocatalysts, while retaining their electrical properties. Neutralized Nafion was also used together with methylene green, electropolymerized on carbon paper for the oxidation of ethanol $[29,44,69]$ and pyruvate [45]. 


\subsection{Mediators attached to a polymer backbone}

As already discussed, the utilization of mediators has a significant role in the establishment of efficient electrical communication between the enzyme and the electrode surface but in many cases the electrode stability can be influenced by mediator leaching. A promising strategy, involving the covalent attachment of the mediator to a polymer backbone has been used in order to overcome this problem (see Figure 2C). Some examples of such mediator systems used in enzymatic biofuel cells are outlined in Table 6 below.

The most notable example, originally introduced by Adam Heller, is the utilization of Os-based redox hydrogels as mediators and immobilization matrices. Heller and co-workers published series of papers, employing GOx as the anodic catalyst and laccase [79-81] or BOD [82-85] for the cathode reaction and PEGDGE was used for cross-linking of the resulting assemblies. The immobilization of enzymes was based on electrostatic interactions because the respective hydrogels were polycationic and enzymes were polyanionic at neutral $\mathrm{pH}[80]$.

The redox potential of the polymer was tuned by variation of the residues forming the Os complexes, which were typically attached to a poly( $N$-vinylimidazole) (PVI) or poly(4-vinylpyryridine) (PVP) backbone for the anode and a co-polymer between PVI and polyacrylamide (PAA) for the cathode.

Table 6. Mediators immobilized on a polymer backbone.

\begin{tabular}{|c|c|c|c|c|c|}
\hline Fuel/Oxidant & Mediator & $\begin{array}{c}\text { Redox } \\
\text { Potential, V } \\
\end{array}$ & $\begin{array}{l}\text { Recalculated Redox } \\
\text { Potential, V vs. SHE }\end{array}$ & pH & Reference \\
\hline \multirow{8}{*}{ glucose } & \multirow{5}{*}{ Os polymer } & $-0.19 \mathrm{Ag} / \mathrm{AgCl}$ & 0.01 & 5 & [80] \\
\hline & & $-0.19 \mathrm{Ag} / \mathrm{AgCl}$ & 0.01 & 7 & [86] \\
\hline & & $0.095 \mathrm{Ag} / \mathrm{AgCl}$ & 0.292 & 5 & [81] \\
\hline & & $-0.16_{\mathrm{Ag} / \mathrm{AgCl}}$ & 0.04 & 7 & [85] \\
\hline & & $-0.11_{\mathrm{Ag} / \mathrm{AgCl}}$ & 0.09 & 5 & [87] \\
\hline & poly(vinylferrocene) & $0.30_{\mathrm{Ag} / \mathrm{AgCl}}$ & 0.50 & 7 & [25] \\
\hline & \multirow{2}{*}{$\begin{array}{c}\text { 2-methyl-1,4- } \\
\text { naphtoquinone } \\
\text { (vitamin } \mathrm{K}_{3} \text { ) }\end{array}$} & $-0.27 \mathrm{Ag} / \mathrm{AgCl}$ & -0.07 & 7 & {$[20]$} \\
\hline & & $-0.25 \mathrm{Ag} / \mathrm{AgCl}$ & -0.05 & 7 & [28] \\
\hline lactose & Os polymer & $0.15 \mathrm{Ag} / \mathrm{AgCl}$ & 0.35 & - & [88] \\
\hline \multirow{2}{*}{ oxygen } & \multirow{2}{*}{ Os polymer } & $0.36_{\mathrm{Ag} / \mathrm{AgCl}}$ & 0.56 & 7 & {$[86]$} \\
\hline & & $0.55_{\mathrm{Ag} / \mathrm{AgCl}}$ & 0.75 & 5 & [79] \\
\hline
\end{tabular}

Worth noting is the introduction of 13-atom long for the anode [80] and 8-atom long for the cathode [79] flexible spacers tethering the complexed Os to the polymer backbone. The improved performance of the respective electrodes was attributed to the long tethers, which allowed not only better approach of the redox centers to the enzyme but also facilitated electron transfer between neighboring redox centers (see Figure 3). So far, biofuel cells based on the concept of Os-based redox hydrogels exhibit the best characteristics in the context of implantable application and other groups have also adopted this procedure for immobilization of GOx [87,89] or other enzymes [18,90]. 
Figure 3. (A) Structure of anodic Os polymer with a 13-atom flexible spacer between the polymer backbone and the Os complex. Reprinted with permission from [86]. Copyright 2002 American Chemical Society. (B) Schematic presentation of electron conduction in Os redox hydrogels. Reprinted from reference [91] with permission from Elsevier.

A)

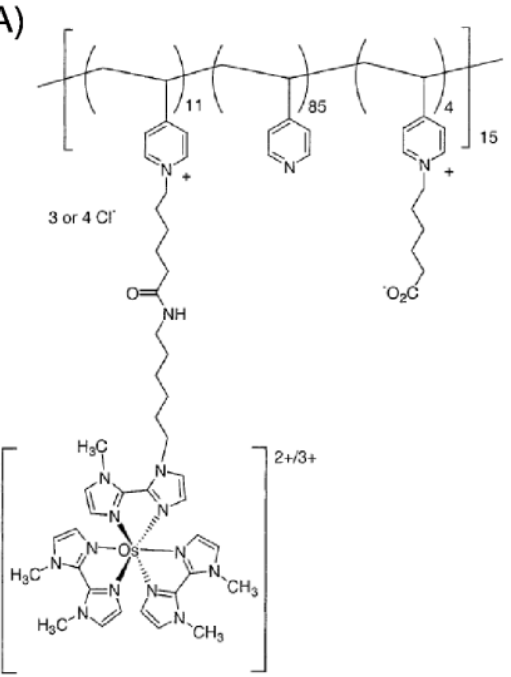

B)

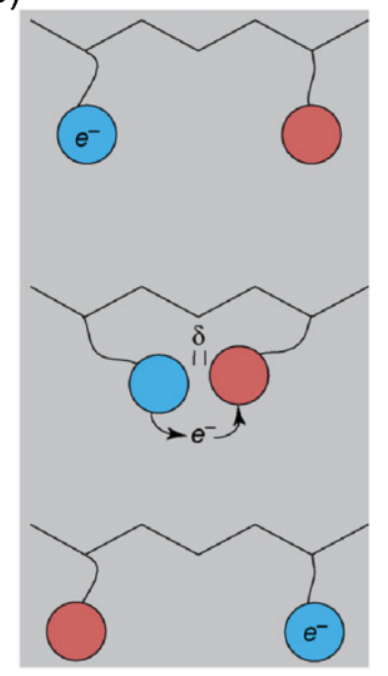

Similar approach in the design of enzymatic electrodes has been employed by other groups. For instance, glucose oxidation anode was prepared by graft polymerization of vinylferrocene and acrylamide onto the carbon black surface after which GOx was adsorbed and cross-linked by GA [25]. Nishizawa and co-workers reported several biofuel cells using $\mathrm{VK}_{3}$-functionalized polymers attached to a PLL [20,60] or a polyallylamine (PAAm) [28] backbone. The polymeric mediator was immobilized together with GDH and diaphorase (EC 1.6.99.-, Dp) on Ketjen Black nanoparticles and the resulting anode was employed in biofuel cell in the presence of soluble NADH.

\section{Kinetics of Bioelectrochemical Reactions on Biofuel Cell Electrodes}

\subsection{Anode reaction}

As it was shown in Table 1 different fuels can be considered for possible application in enzymatic fuel cells. In this context glucose oxidation has been mostly studied due to the intended enzymatic fuel cell application as an implantable power source in human body [18,32,80,82,92]. Besides glucose, oxidation of fructose $[42,43]$ and recently lactose $[18,88]$ have been also studied. In the following section summary of kinetic studies on oxidation of organic fuels in enzymatic fuel cells is reviewed.

\subsubsection{Bioelectrochemical oxidation of glucose.}

Influence of the following parameters like type of enzyme, enzyme modification, type of mediator, glucose concentration, $\mathrm{pH}$, presence of oxygen, buffer concentration, active surface area, stability, etc. on the bioelectrochemical glucose oxidation has been studied. Glucose oxidation is catalyzed by GOx, GDH and CDH $[18,20,32,92,93]$. According to literature, mechanism of glucose oxidation by GDH is 
MET [32,60], while in the case of CDH both MET and DET are possible [18]. The mechanism of glucose oxidation by GOx is still a matter of controversy in the scientific community. Some studies claim DET mechanism, while other due to isolation of the redox active center by a carbohydrate shell claim MET as only possible mechanism.

DET mechanism for glucose oxidation by GOx was reported by several groups $[54,55,61,94,95]$. Dong and co-workers employed CNT's-IL viscous gel as an immobilization matrix for GOx [61]. The anode was tested in a biofuel cell and the observed open-circuit potential (o.c.p.) and short-cut current were attributed to DET of GOx, but the authors did not show any polarization curves for their system under the investigated conditions. Wang et al. immobilized GOx on SWCNT's deposited on silicon substrate and the resulting electrode was employed in a compartmentless and mediatorless biofuel cell configuration [55]. The power output was evaluated in presence of $4 \mathrm{mM}$ glucose and the observed currents were again attributed to DET, although the recently reported activity for glucose oxidation of silicon nanoparticles can compromise these findings [31].

CNT's-hydroxyapatite composite has been also meant to facilitate DET of GOx [54]. This conclusion was based on the observation of a redox peak, which value corresponded to the value for the FAD/FADH 2 couple but the GOx-based anode was engaged in a Nafion-separated biofuel cell with a ferrocene mediator in the anodic compartment. Other authors also considered DET promoted by CNT's but despite the observation of the respective FAD peak there was no current response in presence of glucose [95]. According to them, possible explanation of this phenomenon was the blocking of glucose access to GOx active site due to association of GOx with the CNT's [95].

Common feature of all studies claiming DET in the case of GOx is application of carbon nanomaterials for enzyme immobilization. The DET mechanism is usually evidenced by appearance of $\mathrm{FAD} / \mathrm{FADH}_{2}$ redox peak, but these studies failed to show oxidation currents in presence of glucose which could be probably taken as an indication of absence of DET in the case of GOx. According to a recent review there are indications of possible protein denaturation induced by CNT's [3], consequently the presence of free or exposed FAD close to the electrode surface should not be excluded.

In the case of mediated electron transfer mechanism, amongst the various mediators that were used, worth noting are the Os-based redox hydrogels in the case of GOx [79,80] and CDH [18] and $\mathrm{VK}_{3}$ in the case of GDH [20,32].

Activity of enzymatic electrodes for glucose oxidation can be improved by enzyme purification and/or modification. Purified GOx shows higher catalytic activity for glucose oxidation in comparison to unpurified enzyme [92]. Michaelis-Menten constants of $1.9 \pm 0.2 \mathrm{mM}$ for the purified GOx and $2.5 \pm 0.4 \mathrm{mM}$ for the commercial GOx under argon atmosphere using Os mediator have been reported [92]. Lower activity of unpurified enzyme was attributed to weakening of the electrostatic bond between the polyanionic enzyme and polycationic redox polymer, causing their dissociation and making the "wiring" less effective.

Recently Mano et al. showed that the deglycosylation of GOx yields a fully active deglycosylated enzyme (dGOx) which is capable to oxidize glucose on glassy carbon electrode in absence of any mediator (see Figure 4A) [94]. Onset potential of $-0.490 \mathrm{~V}$ versus $\mathrm{Ag} / \mathrm{AgCl}(-0.29$ vs. SHE), which corresponds to the reversible potential of the $\mathrm{FAD} / \mathrm{FADH}_{2}$ couple was reported (see Figure $4 \mathrm{~B}$ ). They calculated the rate of electron transfer by using the Laviron formalism for GOx and dGOx and 
obtained 0.2 and $1.58 \mathrm{~s}^{-1}$ respectively. Also electron turnover rate for glucose oxidation by dGOx was estimated to be $1300 \mathrm{~s}^{-1}$, while in the case of native enzyme it was about $700 \mathrm{~s}^{-1}$ [94].

Figure 4. (A) Direct electrooxidation of glucose by dGOx adsorbed on glassy carbon. (B) Cyclic voltammograms of GOx (dotted line) and dGOx (solid line) adsorbed on glassy carbon electrodes. Reprinted from reference [94]. Copyright Wiley-VCH Verlag GmbH \& Co. KGaA. Reproduced with permission.
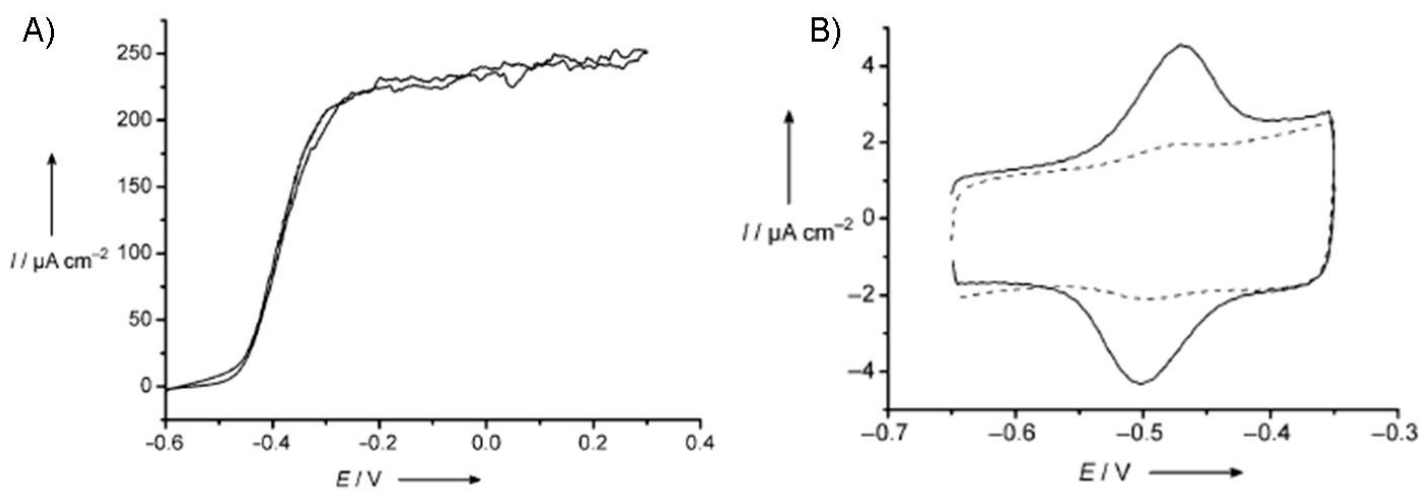

In another paper by Mano and co-authors [82] the influence of the Os loading in different polymers on glucose oxidation by GOx was studied. The obtained results showed that the enzyme activity was increasing with an increase of Os loading, which was attributed to increase of apparent electron diffusion constant in Os polymer.

For biofuel cell operation with fuel and oxidant in the same solution, low sensitivity of the anode reaction to oxygen is very important. This issue has been experimentally investigated for different glucose oxidizing enzymes. It has been shown that in the case of GOx even in the presence of very efficient electron transfer mediators like Os polymer influence of oxygen is still significant [92]. Unlike GOx, $\mathrm{CDH}$ is little sensitive to oxygen. Tasca et al. determined turnover numbers for $\mathrm{CDH}$ in presence of oxygen and two other electron acceptors and obtained $0.09 \mathrm{~s}^{-1}$ for oxygen compared to $16.8 \mathrm{~s}^{-1}$ for 2,6-dihcloroindophenol and $19.6 \mathrm{~s}^{-1}$ for 1,4-benzoquinone [18]. If oxygen is the natural electron acceptor (like in case of GOx, see Table 1), the influence of oxygen is difficult to be neglected even in presence of very efficient electron transfer mediators such as Os polymers.

Influence of the increase of active surface area on enzyme activity was studied by many groups [20,32]. In general addition of carbon nanomaterials (Ketjen Black, CNT's) increases the electrode active surface area and is beneficial for enzyme activity. Sakai et al. studied glucose oxidation by GDH in presence of $\mathrm{Dp}$ and $\mathrm{VK}_{3}$ on glassy carbon and glassy carbon modified by carbon fiber electrodes [32]. Upon addition of carbon fibers catalytic currents for glucose oxidation increased but not linearly in comparison to surface area (e.g., 20 times higher surface area produced 5.9 times higher currents). This was attributed to slow diffusion of $\mathrm{H}^{+}$, which was a product of glucose oxidation, out of the catalyst layer. The accumulation of $\mathrm{H}^{+}$was decreasing $\mathrm{pH}$ value in the catalyst layer and in this way it was changing enzyme activity. To check this assumption they conducted experiments at different buffer concentrations and obtained optimal buffer concentration around 1.0 M, which resulted in almost the same increase in oxidation currents compared to increase of surface area (15 times compared to 20) [32]. 
Togo et al. studied also the influence of addition of Ketjen Black on the activity of GDH VK 3 mediated electrode for glucose oxidation [20]. They obtained 10 times higher currents in presence of Ketjen Black and broadening of the linear range of the concentration dependence (e.g. on glassy carbon electrode linear range was below $5 \mathrm{mM}$, while with Ketjen Black above $10 \mathrm{mM}$ glucose). The addition of carbon nanoparticles did not change the kinetics of glucose oxidation and onset potential for glucose oxidation remained the same, namely about $-0.3 \mathrm{~V} v s$. $\mathrm{Ag} / \mathrm{AgCl}(-0.1 \mathrm{~V} v s$. SHE) [20].

Stability of enzymatic electrodes was usually studied upon its storage under dry conditions or in buffer. After $\mathrm{GDH} / \mathrm{VK}_{3}$ electrodes were stored dry they retained about $80 \%$ of their activity during 7 days, while the activity of electrodes stored under wet conditions decreased significantly over the same time period. It was assumed that the leaching of the enzyme or disruption of electron relay system under wet conditions could be the reason [20].

\subsubsection{Bioelectrochemical oxidation of other fuels.}

Oxidation of fructose by FDH adsorbed on carbon nanomaterials (CNT's or Ketjen Black) was studied $[42,43]$. The open circuit potential (o.c.p.) was $-0.028 \mathrm{~V}$ vs. $\mathrm{Ag} / \mathrm{AgCl}(0.169 \mathrm{~V}$ vs. SHE) at $22{ }^{\circ} \mathrm{C}$ [42] and $-0.05 \mathrm{~V}$ vs. $\mathrm{Ag} / \mathrm{AgCl}\left(0.147 \mathrm{~V}\right.$ vs. SHE) [43] at $25{ }^{\circ} \mathrm{C}$ in presence of $200 \mathrm{mM}$ fructose. These values are close to formal redox potential of $\mathrm{FDH}$ (around $-0.039 \mathrm{~V} v s$. Ag/AgCl; $0.158 \mathrm{~V}$ vs. SHE) which is taken as an indication that the mechanism of fructose oxidation by FDH proceeds through the heme site [43]. Similar to CDH FDH has heme and FAD domains [43]. The observed o.c.p. value suggests that heme domain is oriented to the electrode surface, while FAD domain faces the solution side. Fructose oxidation takes place on FAD domain, which is regenerated in intramolecular electron transfer reaction with the heme domain. Finally heme domain exchanges in direct way electrons with the electrode surface. Also similar to CDH FDH has little sensitivity to oxygen since oxygen is not its natural electron acceptor [42].

Oxidation of lactose by $\mathrm{CDH}$ was studied by Stoica et al. [88] and Tasca et al. [18]. As it was already discussed CDH exhibits both DET and MET due to the presence of heme and FAD domains. DET is usually attributed to action of heme, while MET to action of FAD. Tasca et al. showed recently that in presence of fast electron transfer mediator like Os polymer MET is thermodynamically more favorable than DET (see Figure 5) [18].

Stoica et al. have studied the influence of Os polymer modification and enzyme loading on activity of $\mathrm{CDH}$ for lactose oxidation [88]. Four different types of Os redox hydrogels have been tested. Formal redox potentials of $\mathrm{Os}^{2+/ 3+}$ couples in different polymers were constant (around $150 \mathrm{mV} v \mathrm{~s} . \mathrm{Ag} / \mathrm{AgCl}$; $350 \mathrm{mV}$ vs. SHE). Polymers differed in regard to monomer composition, Os loading as well as the length and flexibility of the spacer chain between the polymer backbone and the Os complex. The observed differences in the activity for glucose oxidation between different polymers were attributed to the different hydrophilicity of the polymer backbones and the local buffer capacity of the polymer film. More hydrophilic polymers were more active. The increase of the ratio of CDH to polymer increased the current for glucose oxidation without showing any maximum in the investigated range of CDH loadings [88]. 
Figure 5. Oxidation of lactose on CDH modified electrodes in the presence (MET) or absence (DET) of Os redox polymer. Reprinted with permission from reference [18]. Copyright 2008 American Chemical Society.

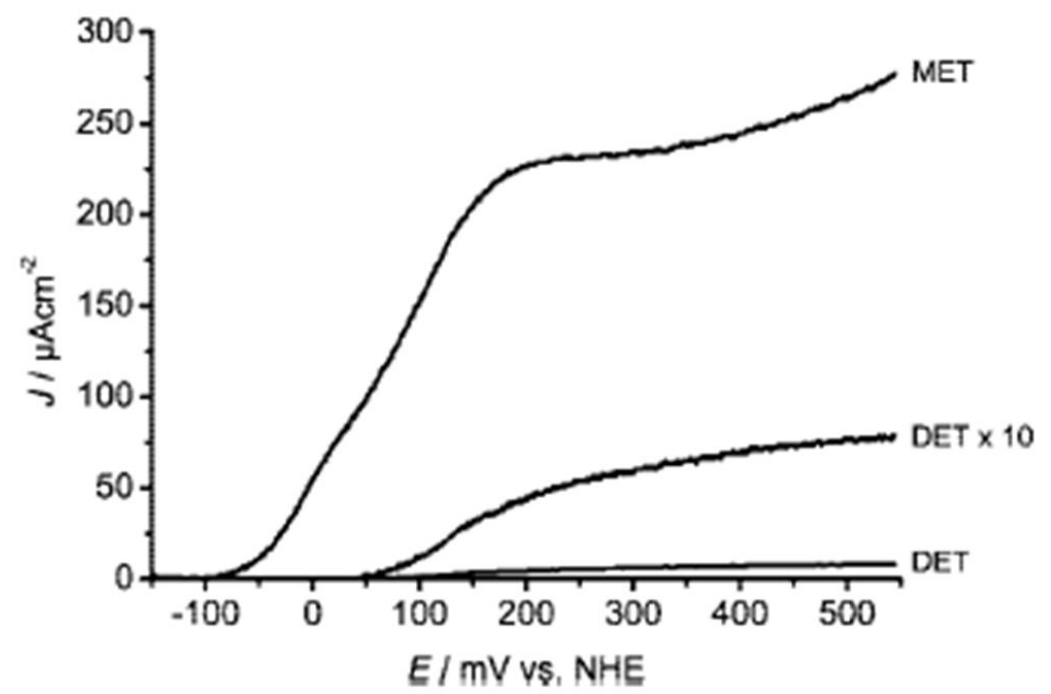

Tasca et al. studied the substrate specificity of $\mathrm{CDH}$ to different fuels in presence of Os polymer as a mediator [18]. CDH was found to be active for oxidation of several sugars like lactose, glucose, cellobiose, maltose, mannose, galactose and xylose. The onset potential for oxidation reaction was practically independent on fuel, but the current densities were very substrate sensitive, which indicated substrate sensitive enzyme kinetics [18].

\subsection{Cathode reaction}

Oxygen is usually used as an oxidant for enzymatic fuel cell operation and the oxygen reduction is catalyzed typically by laccase or BOD. Both enzymes catalyze oxygen reduction to water (see Table 1). The mechanism of oxygen reduction can be DET or MET. Biocathodes consisting of laccase and Os polymer [79] or ABTS as mediators [17] showed superior behavior to platinum (Figure 6A). The better performance of the Os-based biocathode was also proven by scanning electrochemical microscopy (SECM) experiments, where the authors used tip generation-substrate collection mode. The current applied by the tip $\left(I_{t}\right)$ generated oxygen, which was then reduced by the enzyme-modified substrate at current $\left(I_{s}\right)$ defined by the applied potential. The corresponding collection efficiency $\left(I_{s} / I_{t}\right)$ defined by oxygen diffusion at $\mathrm{pH} 7.2$ was reached already at overpotential of $-0.3 \mathrm{~V}$ in the case of BOD cathode versus $-0.65 \mathrm{~V}$ for Pt (Figure 6B) [96].

In case of MET, activity for oxygen reduction can be improved by modifying the mediator molecule. Mano et al. [79] improved the activity of Os polymer for oxygen reduction by introducing long tethers, which increased the apparent electron diffusion constant of Os polymer and efficiency towards oxygen reduction. The apparent electron diffusion coefficient increased with two orders of magnitude (7.6 $\pm 0.3 \mathrm{E}-7$ versus $6.2 \pm 0.8 \mathrm{E}-9 \mathrm{~cm}^{2} \mathrm{~s}^{-1}$ for the previously used polymer) [79]. 
Figure 6. (A) Oxygen reduction by laccase biocathode compared to platinum and glassy-carbon cathodes. Reprinted from [17] with permission from Elsevier. (B) Dependence of the collection efficiency $\left(I_{\mathrm{S}} / I_{\mathrm{T}}\right)$ on the overpotential ( $\eta$ ) in tip generation-substrate collection mode SECM for Pt in $0.5 \mathrm{M} \mathrm{H}_{2} \mathrm{SO}_{4}$ (solid line) and for $\mathrm{Pt}$ (full circles) and "wired" BOD cathode (empty circles) at pH 7.2, 0.2 M phosphate buffer. Reprinted with permission from [96]. Copyright 2003 American Chemical Society.
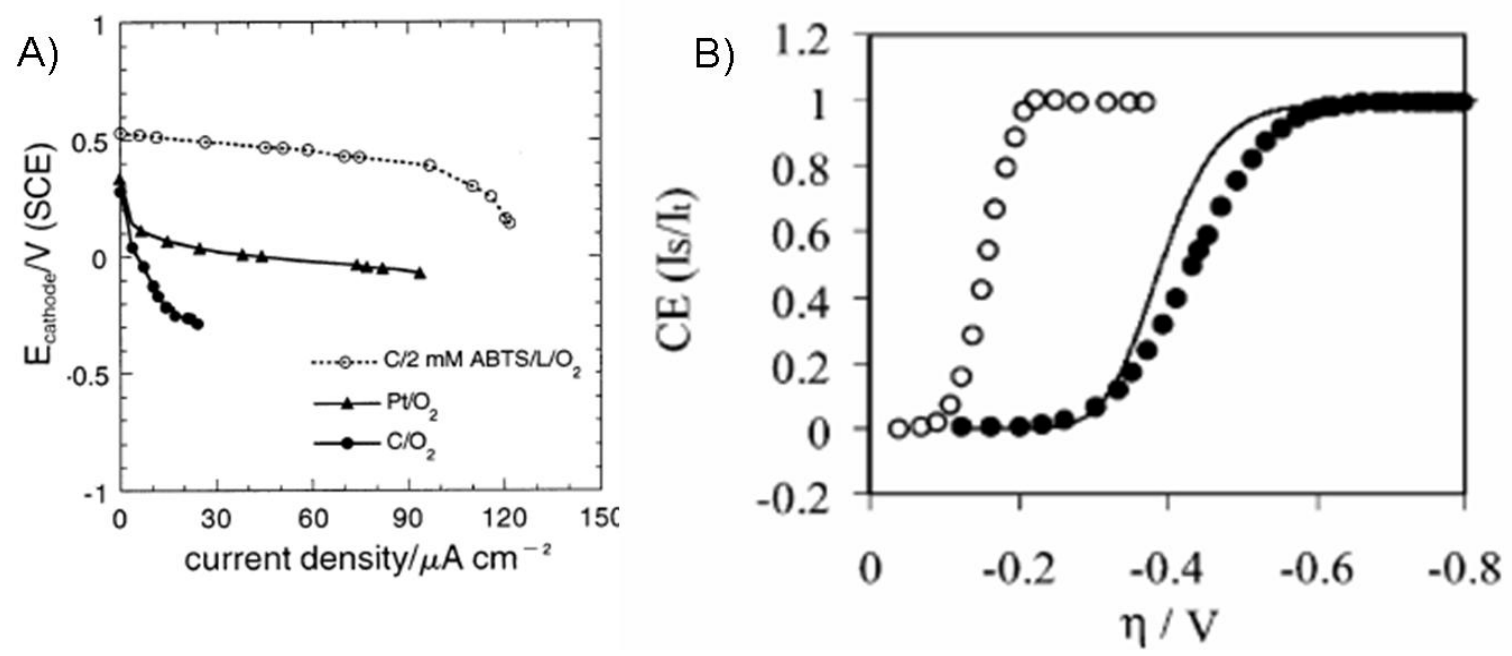

DET for oxygen reduction was reported in case of laccase adsorbed on carbon nanomaterials [43], laccase on carbon nanotubes [12], laccase on carbon electrodes [36] and BOD on spectrographic graphite (SPG) [35]. In the case of DET the mechanism of reaction depends strongly on the type of support [35]. Laccase and BOD were adsorbed on bare SPG or 3-mercaptopropionic acid modified gold (MPA-gold) electrodes. In the case of BOD on SPG electrode DET was observed while in the case of self-assembled monolayer modified gold catalytic action was observed only in presence of mediator. These results indicate that enzyme orientation on two different electrodes is different (Figure 7) [35].

Figure 7. Schematic presentation of proposed mechanisms of DET from electrodes to BOD connected (A) via the T1 site and (B) via the T2/T3 cluster. Reprinted from [35] with permission from Elsevier.

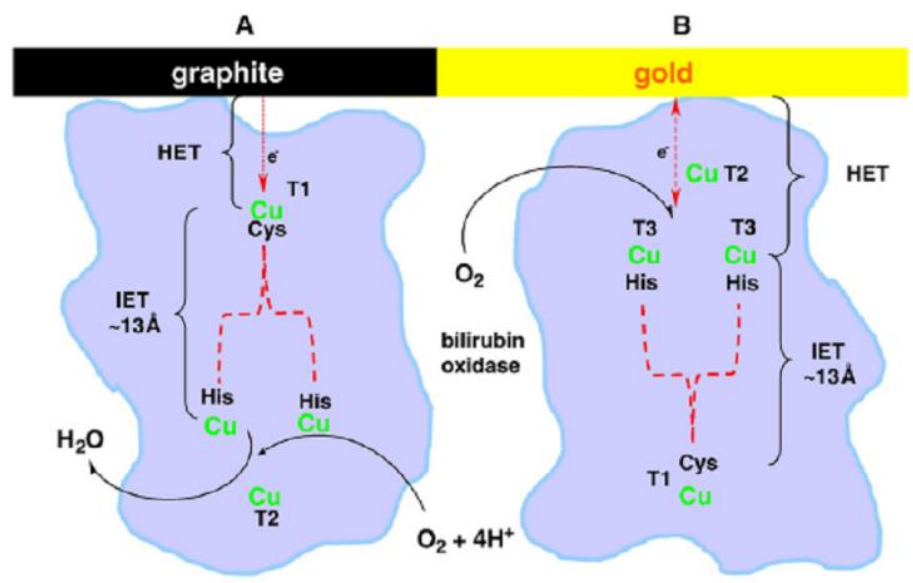


DET oxygen reduction was studied by varying type of enzyme adsorbed on highly-ordered pyrolytic graphite (HOPG) electrode [43]. At pH 5 BOD showed superior performance than the laccase isolated from Rhus vernicifera but lower than the laccase from Trametes sp. (TsLac), which suggested the utilization of the latter in a fructose-oxygen biofuel cell. In order to increase the electrode active surface area and current intensities enzymes were adsorbed on two types of carbon (Ketjen black and carbon aerogel). Higher activity for oxygen reduction was obtained in the case of the TsLac adsorbed on carbon aerogel than on Ketjen Black ( $4 \mathrm{~mA} \mathrm{~cm}^{-2}$ compared to $1 \mathrm{~mA} \mathrm{~cm}^{-2}$ for Ketjen Black) [43].

In general, the oxygen biocathode is limited by the low oxygen concentrations in solution (e.g., $0.229 \mathrm{mM}$ in buffer compared to $9 \mathrm{mM}$ in air). To overcome this limitation Sakai et al. constructed air breathing cathode using BOD adsorbed on carbon fibers which increased significantly current densities for oxygen reduction [32].

\section{Fuel Cell Configurations and Performance}

An overview of some typical enzymatic fuel cell configurations based on literature findings is presented in Table 7 below. As stated above, it is difficult to compare directly the performance of these biofuel cells due to the variety of experimental conditions. Nevertheless, we have enclosed the maximum power densities and the respective fuel concentrations in order to provide an orientation of their typical values.

\subsection{Biofuel cells based on glucose as a fuel and GOx as the biocatalyst}

As it was already discussed, both DET and MET electrode configurations with GOx have been reported. However, DET configurations usually do not provide sufficient evidences for DET mechanism like polarization curves for glucose oxidation and for this reason they will be not commented in the following section. MET configurations can be based on mediators entrapped in different matrices or attached to a polymer backbone.

\subsubsection{Mediators entrapped in different matrices.}

Some characteristic fuel cell configurations in this group were based on the use of ferrocenes as mediators [50,78], mediators immobilized in a polypyrrole matrix [64,76], monoolein cubic phase as immobilization matrix [65] or use of charge transfer complexes [97].

Ferrocene based fuel cell has been reported by Pizzariello et al. [50]. As an oxidant hydrogen peroxide was used in a Nafion-separated biofuel cell configuration. The cathode was formed by spraying a mixture of HRP, ferrocene, graphite particles and a binder on an inert polyester support and coupled with equivalent GOx-based anode. The power extracted from the cell was $0.15 \mu \mathrm{W} \mathrm{cm}$ in presence of $1 \mathrm{mM}$ fuel and oxidizer. The cell exhibited remarkable long-term stability, which was tested by a sophisticated system for supplying and circulating fresh anolyte and catholyte through the cell [50]. 
Table 7. Examples of enzymatic biofuel cells.

\begin{tabular}{|c|c|c|c|c|c|}
\hline Fuel/Oxidant & $\begin{array}{c}\text { Enzymes } \\
\text { Anode/Cathode }\end{array}$ & $\begin{array}{c}\text { Mediators } \\
\text { Anode/Cathode }\end{array}$ & $\begin{array}{c}\text { Power } \\
\text { Density, } \\
\mu \mathrm{W} \text { cm }^{-2}\end{array}$ & $\begin{array}{c}\text { Fuel } \\
\text { Concentration, } \\
\text { mM } \\
\end{array}$ & Reference \\
\hline glucose $/ \mathrm{O}_{2}$ & $\begin{array}{l}\text { GOx/COx, } \\
\text { cytochrome c }\end{array}$ & PQQ/- & 5 & 1 & [49] \\
\hline glucose $/ \mathrm{O}_{2}$ & GOx/laccase & ferrocene/- & 15.8 & 10 & {$[54]$} \\
\hline glucose $/ \mathrm{O}_{2}$ & GOx/BOD & HQS/ABTS & 42 & 10 & {$[76]$} \\
\hline glucose $/ \mathrm{O}_{2}$ & GOx/laccase & TTF/ABTS & 7 & 15 & {$[65]$} \\
\hline glucose $/ \mathrm{O}_{2}$ & GOx/laccase & Os polymer/Os polymer & $137-350$ & 15 & [79-81] \\
\hline glucose $/ \mathrm{O}_{2}$ & GOx/BOD & Os polymer/Os polymer & $50-480$ & 15 & {$[82-85]$} \\
\hline glucose $/ \mathrm{H}_{2} \mathrm{O}_{2}$ & GOx/MP-11 & PQQ/- & 160 & 1 & {$[37]$} \\
\hline glucose $/ \mathrm{H}_{2} \mathrm{O}_{2}$ & GOx/HRP & ferrocene/ferrocene & 0.15 & 1 & {$[50]$} \\
\hline glucose $/ \mathrm{O}_{2}$ & GDH/laccase & azine dyes/- & $58 / 38.7$ & $45 / 60$ & {$[56,67]$} \\
\hline glucose $/ \mathrm{O}_{2}$ & GDH/BOD & azine dyes/- & $52 / 53.9$ & 40 & {$[59,62]$} \\
\hline glucose $/ \mathrm{O}_{2}$ & GDH/BOD & $\mathrm{VK}_{3} /$ ferricyanide & 1450 & 400 & [32] \\
\hline glucose $/ \mathrm{O}_{2}$ & $\mathrm{CDH} /-$ & Os polymer/- & 157 & 100 & [18] \\
\hline lactose $/ \mathrm{O}_{2}$ & $\mathrm{CDH} /$ laccase & Os polymer/Os polymer & 1.9 & 34 & [88] \\
\hline fructose $/ \mathrm{O}_{2}$ & FDH/laccase & $-/-$ & 850 & 200 & [43] \\
\hline fructose $/ \mathrm{O}_{2}$ & FDH/BOD & $-/-$ & 126 & 200 & [42] \\
\hline methanol/ $\mathrm{O}_{2}$ & $\mathrm{ADH} /-$ & benzylviologen/- & 670 & 100 & {$[30]$} \\
\hline ethanol $/\left(\mathrm{H}_{2} \mathrm{O}_{2}\right)$ & 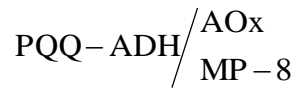 & $-/-$ & 1.5 & 25 & {$[46]$} \\
\hline ethanol $/ \mathrm{O}_{2}$ & $\begin{array}{l}\text { ADH } \\
\text { AldDH }\end{array} /$ BOD & $\begin{array}{l}\text { poly(methylene } \\
\text { green }) / \operatorname{Ru}(\mathrm{bpy})_{3}\end{array}$ & 460 & 1 & [69] \\
\hline glycerol/ $\mathrm{O}_{2}$ & $\begin{array}{l}\text { PQQ-ADH } \\
\text { PQQ-AldDH } \\
\text { OOx }\end{array}$ & $\begin{array}{l}\text { poly(methylene } \\
\text { green)/- }\end{array}$ & 1320 & 100 & [47] \\
\hline pyruvate/ $\mathrm{O}_{2}$ & $\begin{array}{l}\mathrm{PDH} \\
\ldots *\end{array} /-$ & $\begin{array}{l}\text { poly(methylene } \\
\text { green)/- }\end{array}$ & 930 & 100 & [45] \\
\hline
\end{tabular}

*PDH is the first enzyme in a cascade comprising enzymes from the citric acid cycle

Tingry and co-workers introduced several biofuel cell configurations based on immobilization of enzyme and mediator in polypyrrole $[64,73,76]$. After optimization of the polypyrrole layer thickness, the electrodes based on GOx/HQS and BOD/ABTS were employed in a concentric cell configuration, which demonstrated maximum power output of $42 \mu \mathrm{W} \mathrm{cm}{ }^{-2}$ at $10 \mathrm{mM}$ glucose concentration [76]. The stability of the electrodes with entrapped enzymes was also compared to electrodes prepared by covalent grafting [73]. The biofuel cell power output was lower in the case of covalently attached enzymes $\left(20 \mu \mathrm{W} \mathrm{cm}{ }^{-2}\right.$ at $\left.0.3 \mathrm{~V}\right)$ but remained constant after 45 days intermittent use. The improved stability was discussed in the context of enzyme denaturation or mediator leaching from the more permeable polypyrrole matrix in the case of entrapped enzyme electrodes [73]. In the case when polypyrrole nanowires (see Figure 8A) were used as a matrix for the same enzyme/mediator systems the fabricated biofuel cells exhibited higher power density (by two orders of magnitude) compared to 
the film-type biofuel cells [74]. The increase was ascribed to the increase in surface area and enzyme loading. The influence of nanowires length was also tested and as the length was reduced from $16 \mu \mathrm{m}$ to $8 \mu \mathrm{m}$, o.c.p. increased (see Figure $8 \mathrm{~B}$ ) but the maximum power density decreased from about 280 to $150 \mu \mathrm{W} \mathrm{cm}{ }^{-2}$ [74].

A membraneless cell based on GOx and laccase was constructed with monoolein cubic phase as immobilization matrix [65]. The performance of the cell employing ABTS as the cathodic mediator and different anodic mediators was tested. The most stable cell was obtained when TTF was employed as anodic mediator with o.c.p. of $0.45 \mathrm{~V}$ and a maximum power density of $c a .7 \mu \mathrm{W} \mathrm{cm}{ }^{-2}$ at voltage of about $0.125 \mathrm{~V}$ [65]. In another report, where TTF was immobilized in a polyion complex and MWCNT's, the nanotubes were found to improve the anode performance in terms of current increase and shift to more negative potentials [75]. After combination with identical BOD/ABTS cathodes, the membraneless biofuel cell exhibited o.c.p. of $0.65 \mathrm{~V}$ and a maximum power density of $150 \mu \mathrm{W} \mathrm{cm}{ }^{-2}$ at $0.35 \mathrm{~V}$ in presence of $100 \mathrm{mM}$ glucose at $37{ }^{\circ} \mathrm{C}$ [75].

The anode architecture, used by our group (discussed by the anode architectures based on immobilized mediators) comprising CTC based on TTF and TCNQ was coupled with a conventional PEM-based Pt cathode and the performance of the resulting flow-through cell was tested under different conditions [97].

Figure 8. (A) Field emission scanning electron microscopy (FESEM) images of $80 \mathrm{~nm}$ diameter polypyrrole-HQS-GOx nanowires grown using anodized aluminum oxide (AAO)-Si template. The inset shows a cross-sectional view. (B) Dependence of the power density on the cell voltage for biofuel cells employing nanowires with different length. Reprinted from [74] with permission from Elsevier.
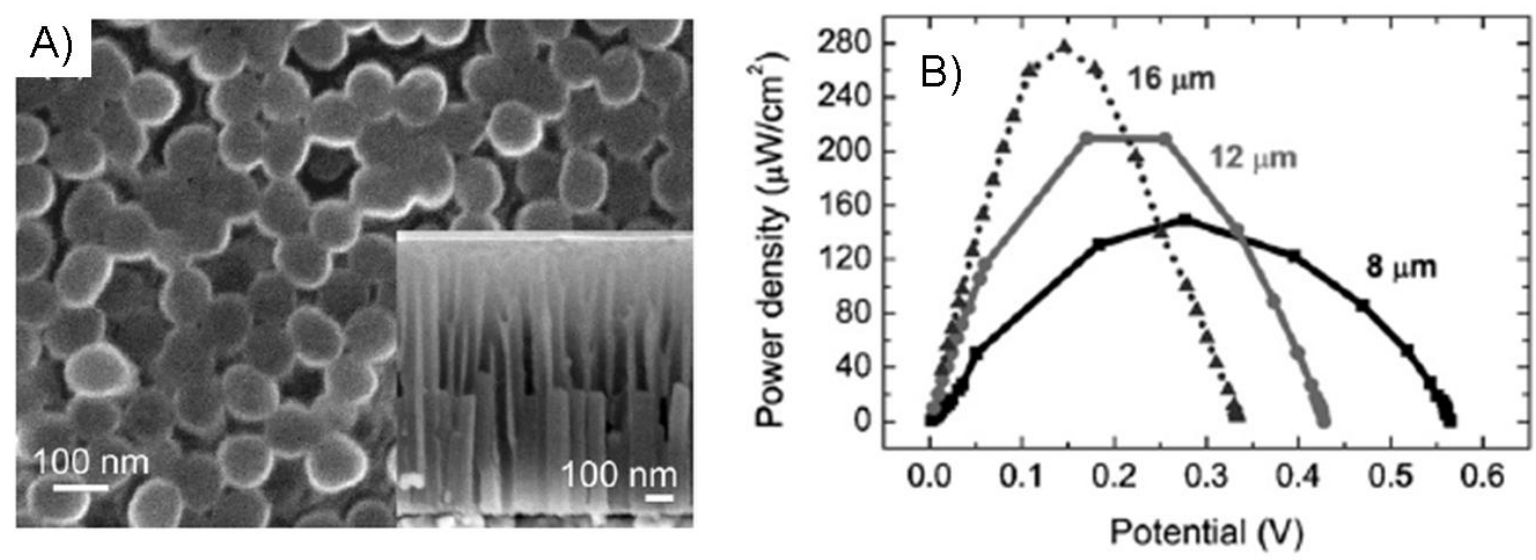

7.1.2. Mediators attached to a polymer backbone

The advantages of systems, employing mediator attached to a polymer backbone were already addressed in the section regarding the existing electrode architectures. Ferrocene-mediated glucose oxidation anode based on this approach was incorporated in a membrane-electrode assembly (MEA)-type fuel cell with a Pt catalyst for gas-phase oxygen reduction [25]. The cell performance was 
tested under flow conditions at room temperature in presence of $100 \mathrm{mM}$ glucose and results indicated increased current and power output after impregnation of the GOx anode with 1\% Nafion solution [25].

Other, more notable examples of enzymatic biofuel cells using mediator-polymer assemblies were based on the Os redox hydrogels, which were discussed above. The performance of a biofuel cell using (PVP-[Os $\left.\left.\left(N, N^{\prime} \text {-dialkylated-2,2'-biimidazole }\right)^{3}\right]^{2+/ 3+}\right)$ for immobilization of $\mathrm{GOx}$ and (PAA-PVI-[Os(4,4'-dichloro-2,2'-bipyridine $\left.)_{2} \mathrm{Cl}\right]^{+/ 2+}$ ) for immobilization of BOD was studied at different conditions [83]. The influence of $\mathrm{pH}$, temperature and glucose and chloride concentration in oxygen or air atmosphere was tested (Figure 9). It was found that the cell power was not affected by chloride concentration up to $0.15 \mathrm{M}$, which was a positive result, since chloride anions are a common inhibitor of multi-copper oxidases, with a typical concentration of $0.14 \mathrm{M}$ in physiological fluids.

Figure 9. Dependence of the power density of Os polymer based biofuel cell on (A) $\mathrm{pH}$, (B) temperature and $(\mathrm{C})$ chloride concentration under constant polarization at $0.52 \mathrm{~V}$ in presence of $15 \mathrm{mM}$ glucose. Reprinted with permission from [83]. Copyright 2003 American Chemical Society.
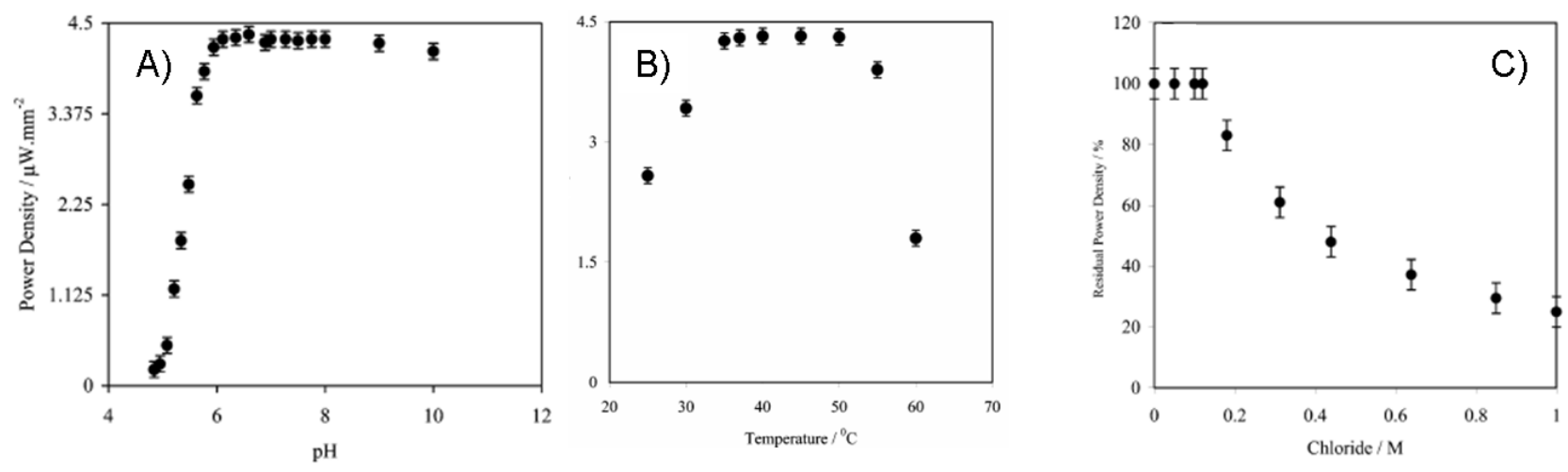

The progress in the design of the redox hydrogels based on the respective biofuel cells performance can be clearly followed. For instance, superior fuel cell performance $\left(268 \mu \mathrm{W} \mathrm{cm}{ }^{-2}\right.$ at $0.78 \mathrm{~V}$ in $15 \mathrm{mM}$ glucose solution) was achieved by introducing a 13-atom long flexible spacer in the anodic polymer and combination with a laccase-based cathode [80]. The operation in a membraneless configuration was realized by maintaining lower rate of electron transfer to oxygen than to the redox polymer [80]. This approach allowed also for power density of $480 \mu \mathrm{W} \mathrm{cm}$ at $0.6 \mathrm{~V}$ at $\mathrm{pH} 7.2$ with BOD as the cathodic biocatalyst [82]. Another worth mentioning achievement was a power density of $350 \mu \mathrm{W} \mathrm{cm}{ }^{-2}$ at $0.88 \mathrm{~V}$ with laccase at $\mathrm{pH} 5$ in stagnant solution with $15 \mathrm{mM}$ glucose [79]. The high power density was attained due to the introduction of 8-atom spacer in the cathodic polymer, analogous to the flexible tether in the case of anodic enzyme.

Carbon fibers with a length of $2 \mathrm{~cm}$ and a diameter of $7 \mu \mathrm{m}$ were used as a support in nearly all the studies by Heller and co-workers. The electrodes were also implanted in a grape and it was found that the power output depended on the position of the cathode fiber. The cell exhibited higher power density $\left(240 \mu \mathrm{W} \mathrm{cm}{ }^{-2}\right.$ at $\left.0.52 \mathrm{~V}\right)$ if the cathode fiber was located near the skin of the grape due to the higher oxygen concentration, than if it was located near the center of the grape $\left(47 \mu \mathrm{W} \mathrm{cm}^{-2}\right)$ [83].

Recently, Mano reported improved cell power of $280 \mu \mathrm{W} \mathrm{cm}{ }^{-2}$ at $\mathrm{pH} 5$ in presence of $5 \mathrm{mM}$ glucose using GOx from another source (Penicillium pinophilum) and high stability under continuous 
operation at $0.88 \mathrm{~V}$ [93]. Moreover, since the commercial samples of GOx from Aspergilus niger contain various impurities and the composition of the same supplier varies from batch to batch, two-fold increase in maximum power density was observed when purified GOx was used [92].

In summary, the enzymatic biofuel cells based on the concept of Os-based redox hydrogels exhibit the best characteristics so far in the context of implantable application and the approach has been adopted by other groups as a standard procedure for testing MET [18,88,90].

\subsection{Biofuel cells based on glucose as a fuel and GDH and CDH as biocatalysts}

Other common enzyme for glucose oxidation, employed in enzymatic biofuel was GDH. As shown above in the text, the enzyme's natural electron acceptor is NAD and not oxygen as in the case of GOx. This is a significant advantage when aiming a membraneless configuration due to the reduced cross-over of reactants but the utilization of soluble co-factor excludes the application of such systems as implantable devices.

For instance, several biofuel cells based on azine dyes as mediators for the regeneration of the NADH co-factor were constructed by Mao and co-workers [56,59,62,66]. The biofuel cells exhibited reasonable performance at rather high glucose concentrations, ranging from 30 to $45 \mathrm{mM}$. The use of CNT's allowed DET at the cathode and when BOD immobilized on carbon fiber microelectrodes was employed, the enhancement of mass transport allowed cathodic current densities of $105 \mu \mathrm{A} \mathrm{cm}{ }^{-2}$ under ambient air and $255 \mu \mathrm{A} \mathrm{cm}^{-2}$ under oxygen atmosphere at $0.3 \mathrm{~V} v$ s. $\mathrm{Ag} / \mathrm{AgCl}$ (0.5 V vs. SHE) [59]. In the same reference a promising approach was introduced by the co-immobilization of ascorbate oxidase (EC 1.10.3.3) on both electrodes in order to eliminate the interference by ascorbic acid. The respective biofuel cell demonstrated high tolerance against ascorbic acid in buffer and improved performance in human serum. The power output in serum was still lower than in buffer, suggesting the existence of other kinds of interfering species [59].

In other studies $\mathrm{VK}_{3}$ was employed to regenerate $\mathrm{Dp}$, which was oxidizing the NADH reduced by GDH (see Figure 10) [28]. The resulting anodes were combined with polydimethylsiloxane-coated Pt $[20,28]$ or a BOD-based cathode [60] and the respective biofuel cells performance was tested in presence of soluble NADH. The same approach for the cathode architecture was used in a work by Kano and co-workers but this time all components including NADH were immobilized in a polyion matrix [32]. Combination with a BOD-based gas-phase cathode and a cellophane separator allowed the fabrication of a passive-type biofuel cell with high output. The cell generated $1.45 \mathrm{~mW} \mathrm{~cm} \mathrm{c}^{-2}$ at $0.3 \mathrm{~V}$ (o.c.p. $0.8 \mathrm{~V}$ ) in presence of $0.4 \mathrm{M}$ glucose and after connection in series of two fuel cell stacks (two biofuel cells in parallel) operation of portable electronic devices was achieved [32].

$\mathrm{CDH}$ was also used as anodic enzyme in biofuel cells. CDH and SWCNT's were entrapped in Os polymer and the resulting anode was employed together with a $\mathrm{Pt}$ cathode in a whole fuel cell configuration, which showed o.c.p. of $0.5 \mathrm{~V}$ and a maximum power density of $157 \mu \mathrm{W} \mathrm{cm}{ }^{-2}$ in $100 \mathrm{mM}$ glucose solution [18]. In another study $\mathrm{CDH}$ adsorbed on graphite electrode was engaged together with identical laccase cathode in a membraneless and mediatorless biofuel cell [40]. The cell demonstrated lower performance in presence of glucose compared to lactose and cellobiose and reduced stability when the electrolyte was mixed, which was attributed to enzyme desorption from the electrode surface. The possibility of DET, the utilization of various fuels and the lower affinity to 
oxygen compared to other electron acceptors define $\mathrm{CDH}$ as a powerful alternative to GOx for enzymatic biofuel cell applications.

Figure 10. Reaction schemes in a biofuel cell based on $\mathrm{GDH} / \mathrm{Dp} / \mathrm{VK}_{3}$ bioanode and $\mathrm{Pt}$ cathode. Reprinted from [28] with permission from Elsevier.

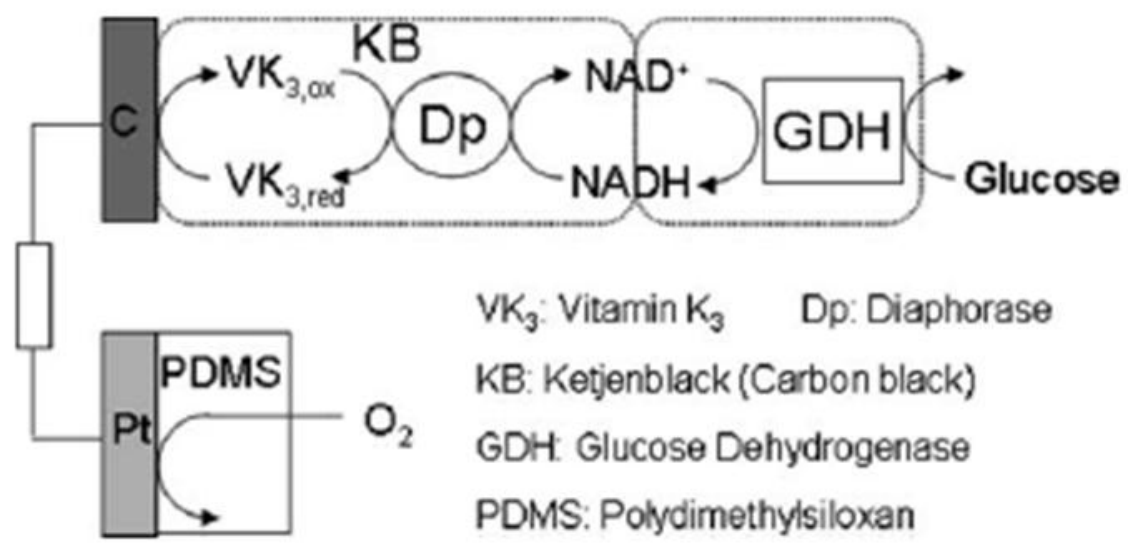

\subsection{Biofuel cells based on fuels other than glucose}

The ability of $\mathrm{CDH}$ to oxidize different sugars was already addressed, but its high affinity towards lactose motivated the development of a membraneless Os polymer based lactose-oxygen biofuel cell [88]. The cell comprising laccase as the cathodic catalyst demonstrated maximum power density of about $1.9 \mu \mathrm{W} \mathrm{cm}{ }^{-2}$ at $0.28 \mathrm{~V}$ in presence of $7.4 \mathrm{mM}$ lactose at $\mathrm{pH} 4.3$ and the current density was found to be limited by the anodic process, most likely due to the limited amount of immobilized CDH. Os-mediated bioelectrocatalysis allowed also the coupling of tryptophan repressor-binding protein from Archaeoglobus fulgidus with a Pt cathode in a membraneless biofuel cell with $8 \mathrm{mM} \mathrm{NADH}$ as a fuel [90].

Fructose oxidation by FDH was used in biofuel cells based on DET [42,43]. In one of the configurations based on cellulose-MWCNT's matrix the cell showed maximum current density of $577 \mu \mathrm{A} \mathrm{cm}^{-2}$ and power density of $126 \mu \mathrm{W} \mathrm{cm}{ }^{-2}$ in presence of $200 \mathrm{mM}$ fructose at $\mathrm{pH} 5$ and room temperature using BOD as the cathode enzyme [42]. Better performance under the same conditions was achieved by simple adsorption of FDH on Ketjen Black-modified carbon paper and combination with laccase immobilized on carbon aerogel support. The maximum power density reached $850 \mu \mathrm{W} \mathrm{cm}$ at $0.41 \mathrm{~V}$ under stirring (see Figure 11) [43].

Enzymatic fuel cell utilizing alcohols as fuels were constructed as well. Full oxidation of methanol to $\mathrm{CO}_{2}$ by a cascade of enzymes and subsequent regeneration of NADH by Dp and benzylviologen was addressed already in 1998 by Palmore et al., but all components taking part in the bioelectrochemical reaction, including enzymes were dissolved in the anolyte [30]. In another MET-based system employing PQQ-dependent ADH the two-compartment cell generated power of $0.25 \mathrm{~mW} \mathrm{~cm}{ }^{-2}$ at $0.67 \mathrm{~V}$ in presence of $1 \%$ methanol and soluble TMPD as mediator [24]. The high power density and high o.c.p. $(1.4 \mathrm{~V})$ were achieved by using potassium permanganate cathode. 
More widely exploited alcohol in the development of biofuel cells was ethanol $[44,46,51,68,69]$. Worth noting is the employment of multi-enzyme cascades starting with ADH and AldDH for bioelectrochemical mimicking of the citric acid cycle reported by Minteer et al. [44].

Figure 11. Dependence of power density on current density generated by one-compartment fructose-oxygen biofuel cell without (1) and with stirring (2) in presence of $200 \mathrm{mM}$ fructose at $25{ }^{\circ} \mathrm{C}$. Reprinted from reference [43] with permission of the PCCP Owner Societies.

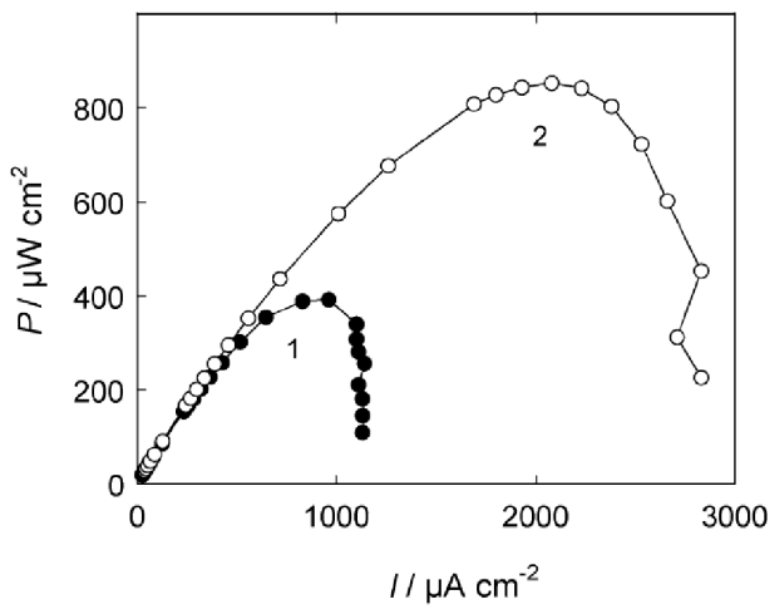

Figure 12. (A) Schematic presentation of a biofuel cell based on ethanol as a fuel for bioelectrochemical mimicking of the citric acid cycle. (B) Representative power curves of biofuel cells employing different number of enzymes. Reprinted from [44] with permission from Elsevier.
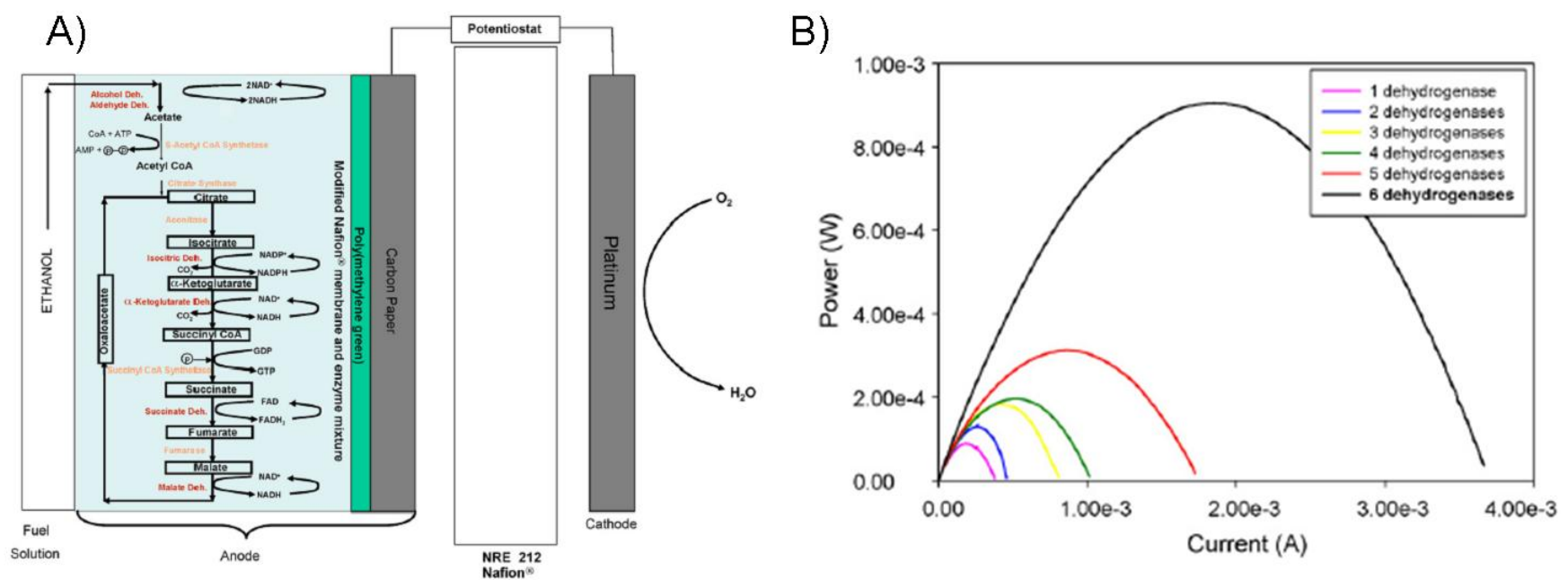

$\mathrm{ADH}$ and AldDH catalyzed the oxidation of ethanol to acetate, which in the presence of CoA and ATP was converted to acetyl-CoA by acetyl-coenzyme A synthetase (EC 6.2.1.1) and further entered the Kreb's cycle (see Figure 12A). After combination with a Pt cathode, the influence of the number of immobilized enzymes on the performance of the two-compartment biofuel cell was tested. In presence of $100 \mathrm{mM}$ ethanol the respective cells exhibited maximum power density ranging from $116 \mu \mathrm{W} \mathrm{cm}{ }^{-2}$ 
in the case of one enzyme $(\mathrm{ADH})$ to $1.01 \mathrm{~mW} \mathrm{~cm}^{-2}$ when all six enzymes were employed (see Figure 12B) [44].

A very interesting approach for the design of a biofuel cell was demonstrated by Ramanavicius et al., by the introduction of a membraneless and mediatorless system, which utilized ethanol and glucose [51]. ADH was simply adsorbed on a graphite anode and served for the oxidation of ethanol and GOx and MP-8 were co-immobilized on the cathode, where MP-8 catalyzed the reduction of hydrogen peroxide, generated as a by-product from the oxidation of glucose by GOx (see Figure 13A). Unfortunately, no data for the power output was presented but the cell generated the highest voltage and current densities in presence of $10 \mathrm{mM}$ glucose and $10 \mathrm{mM}$ ethanol, compared to the cases, when only glucose, ethanol or hydrogen peroxide were used (see Figure 13B) [51].

Figure 13. (A) Schematic configuration of a biofuel cell employing ethanol and glucose as fuels and QH-ADH and MP-8/GOx as catalytic anode and cathode, respectively. (B) Current-voltage behavior of the respective biofuel cell in presence of (1) $10 \mathrm{mM}$ hydrogen peroxide, (2) $10 \mathrm{mM}$ of glucose, (3) $10 \mathrm{mM}$ of ethanol and (4) $10 \mathrm{mM}$ of ethanol and $10 \mathrm{mM}$ of glucose. Reprinted from [51] with permission from Elsevier.
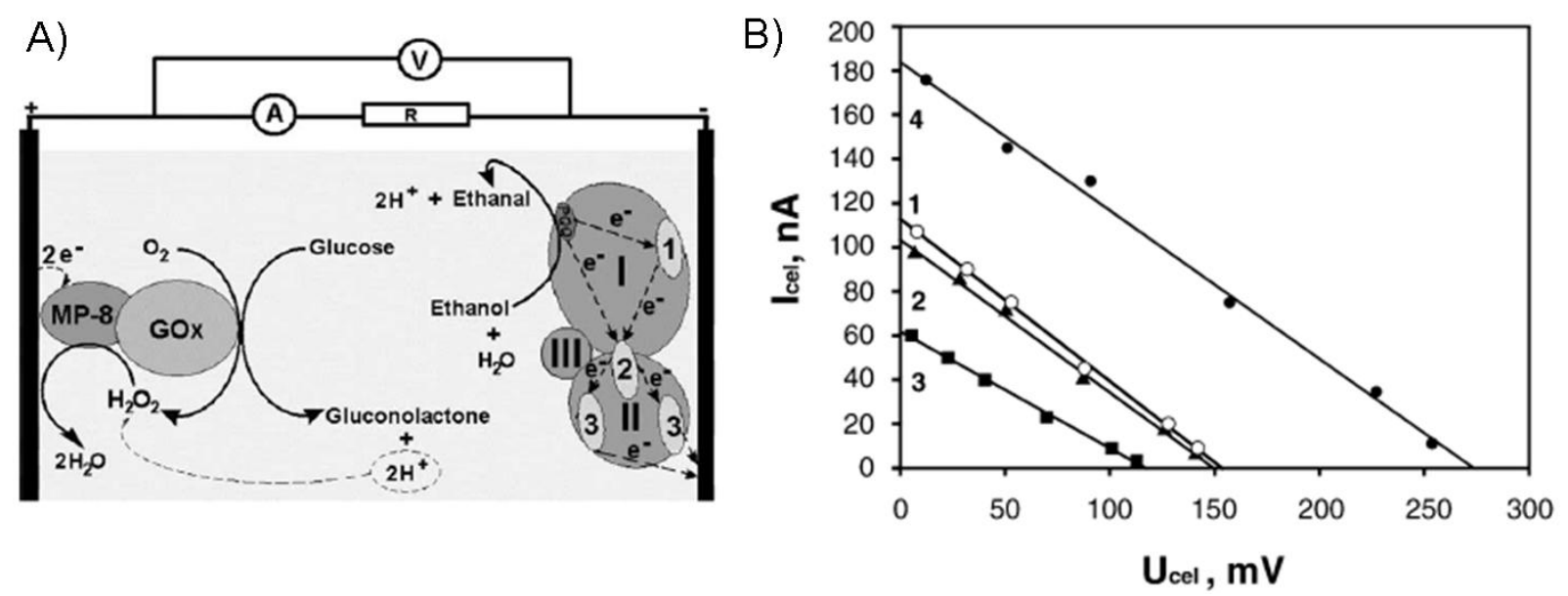

Minteer and co-workers demonstrated also the utilization of multi-enzyme systems for glycerol oxidation [23,47]. An enzyme cascade immobilized in neutralized Nafion allowed the complete oxidation of glycerol to $\mathrm{CO}_{2}$ and a maximum power density of $0.445 \mathrm{~mW} \mathrm{~cm}{ }^{-2}$ in presence of $100 \mathrm{mM}$ substrate. The use of high surface area MWCNT's as immobilization matrix increased the power up to $1.32 \mathrm{~mW} \mathrm{~cm}^{-2}$ under the same conditions [47].

The MET-based cascade approach was used also for complete pyruvate oxidation [45]. The system employing five dehydrogenases achieved a maximum power density of $0.93 \mathrm{~mW} \mathrm{~cm}{ }^{-2}$ in presence of $100 \mathrm{mM}$ pyruvate. The same group reported also a biofuel cell based on pyruvate oxidation by immobilized mitochondria, which could be considered as a cellular compartment containing dissolved enzymes in the internal matrix [98]. Under the same conditions the organelle-based fuel cell exhibited a maximum power density of $0.20 \mathrm{~mW} \mathrm{~cm}^{-2}$ and the nearly 5 -fold increase was attributed to the higher volumetric catalytic activity of isolated enzymes and the elimination of additional resistances and mass transport limitations associated with the mitochondrial membrane [45]. 
Analogous to conventional PEM fuel cells, there are attempts of biofuel cells using hydrogen and oxygen as a fuel and oxidant. There are reports of systems involving microbial-based [99] as well as enzyme-based hydrogen oxidation [48]. In the latter study Armstrong et al. employed MBH from Ralstonia eutropha and after combination with a laccase cathode constructed a membraneless biofuel cell. MBH exhibited high tolerance to oxygen and $\mathrm{CO}$ (a common inhibitor for hydrogen catalysts) and the cell generated an o.c.p. of $0.97 \mathrm{~V}$ and power output of around $7 \mu \mathrm{W} \mathrm{cm}^{-2}$ [48].

\subsection{Long-term stability testing}

Essential for the future application of enzymatic biofuel cells is their long-term stability. There are a limited number of studies, where long-term testing has been addressed and some examples will be discussed here. For instance, Mano et al. tested the stability of enzymatic fuel cell based on GOx and BOD immobilized in Os redox hydrogels under continuous operation at $0.52 \mathrm{~V}$ during one week and found that the cell lost around 6\% of its initial power per day [86]. In another report Wu et al. investigated the long-term stability of fructose-air fuel cell based on DET as well as the stability of the respective individual bioelectrodes in a three-electrode system [42]. The cell power reached around $50 \%$ of its initial value after $90 \mathrm{~h}$ continuous operation at $0.35 \mathrm{~V}$. The higher stability compared to previously reported DET-based biofuel cells was attributed to the hydrophilic properties of the cellulose-MWCNT's matrix, which provided a biocompatible environment for the enzymes and hindered leaching [42].

The stability of glucose-hydrogen peroxide biofuel cell was studied by Pizzariello et al. [50]. Long-term testing (30 days) was achieved through a sophisticated system of pumps supplying fresh anolyte and catholyte. The cell exhibited remarkable stability with only $2.32 \%$ decrease in voltage output after operation for 15 days with glucose as a fuel and $2.5 \%$ decrease with diluted corn syrup as a fuel [50]. In another study by Kim and co-workers, the long-term stability of a glucose-oxygen biofuel cell was tested [27]. The authors found out that power output decreases significantly after $2 \mathrm{~h}$ of continuous operation but a replacement of the used MEA with a new one allowed almost complete regeneration of the initial activity. The loss of activity was attributed to deactivation of the membrane by cations from the buffering solution, which competed with protons for the anionic sulfonic sites of Nafion and decreased its overall proton conductivity. The improved stability of the cell in unbuffered solution, compared to sodium and ammonium phosphate during a $15 \mathrm{~h}$ long-term stability test served as a further attestation of this conclusion [27].

\section{Typical Designs of Enzymatic Fuel Cells}

Enzymatic fuel cell are still at level of proof-of-concept and most reported enzymatic fuel cell systems consist of enzymatic electrodes simply immersed in corresponding buffer solution. Still there are few more sophisticated fuel cell designs like microfluidic enzymatic fuel cells [60,63,100,101], concentric biofuel cell [11,76], enzymatic fuel cell with air breathing cathode [32,102], designs which use MEA [27] and modular stack cells [43,103] (see Figure 14) which will be highlighted here. 


\subsection{Microfluidic systems}

The intended application of enzymatic biofuel cells as small-scale (implantable) power devices is tightly associated with challenging design issues, concerning the miniaturization of such systems. In this context, in parallel with the research on novel bioelectrodes with an improved performance, there is emerging research field addressing microfluidic biofuel cells. The biofuel cell technology is still not mature and there are no end solutions for the problems, regarding the limited power output and the low long-term stability. Nevertheless, the recent advances in microfabrication techniques empowered the merging of microfluidics- and biofuel cells-based systems and initial efforts for the investigation of mass transport effects on micro level have been already reported.

The studies on microfluidic biofuel cells usually employ diffusional enzyme and mediator, dissolved in the electrolyte solution flowing through the microchannel. The typically low flow rates and micrometer-range dimensions define laminar flow conditions and the resulting lack of convective mixing allows the elimination of a physical membrane to separate the anolyte and catholyte flows.

Figure 14. Schematic presentation of (A) microfluidic biofuel cell device; (B) concentric biofuel cell; (C) miniature biofuel cell consisting of an enzymatic anode and an air-breathing Pt cathode; (D) standardized modular stack cell platform. (A) and (B) reprinted from [101] and [76] with permission from Elsevier. (C) and D) reprinted from [27] and [103]. Copyright Wiley-VCH Verlag GmbH \& Co. KGaA.
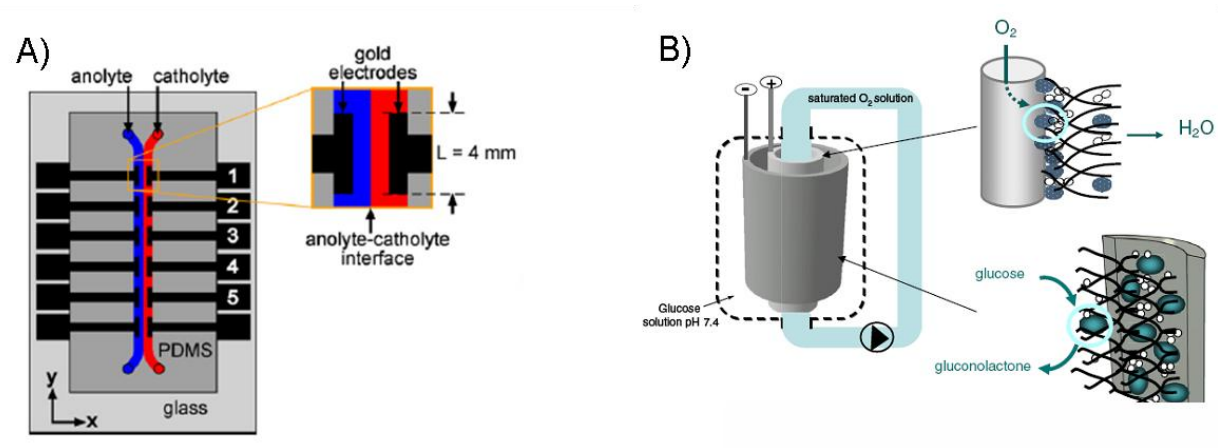

C)
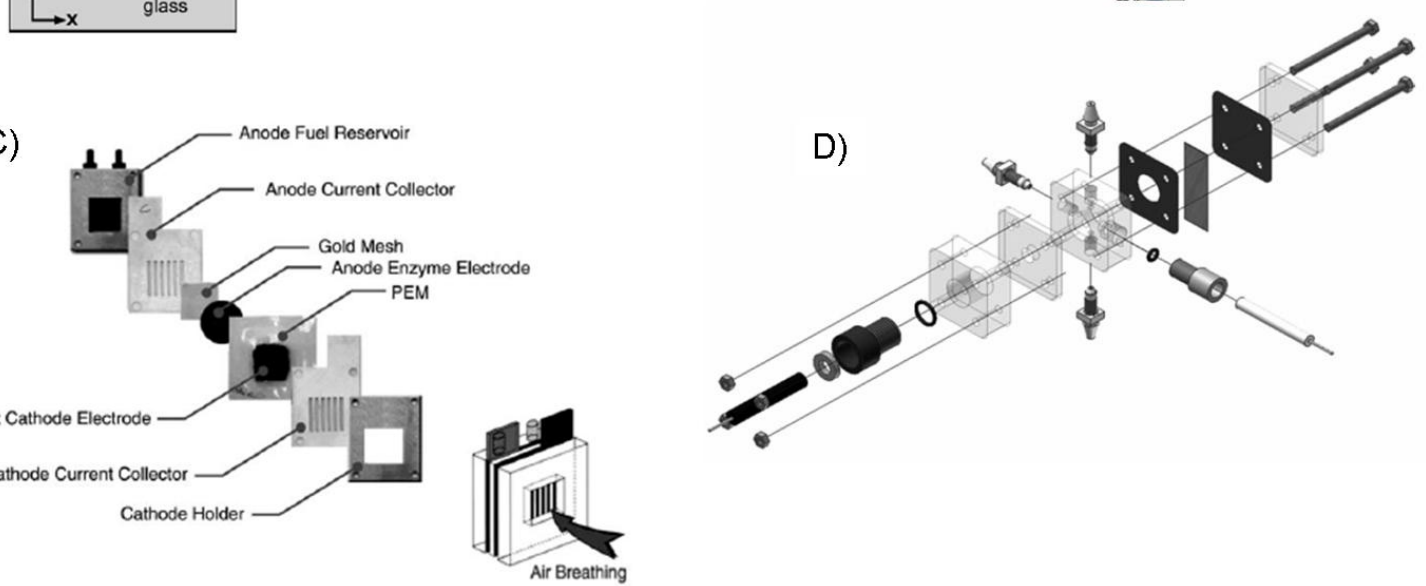

For instance, Tingry and co-workers recently reported a microfluidic biofuel cell with a Y-shaped channel, based on soluble GOx and potassium ferricyanide for the anodic reaction and laccase and ABTS for the cathodic reaction [100,104]. The influence of flow rates on the cell performance was investigated and a maximum power density of $110 \mu \mathrm{W} \mathrm{cm}{ }^{-2}$ in $10 \mathrm{mM}$ glucose at $1000 \mu \mathrm{L} \mathrm{min}^{-1}$ flow 
rate was achieved. Moreover, the pumping power to sustain the necessary flow was compared with the delivered power by the cell and it was found that the ratio of input power to the output power increased from $1.5 \%$ at $100 \mu \mathrm{L} \mathrm{min} \operatorname{mos}^{-1}$ to $76 \%$ at $1000 \mu \mathrm{L} \mathrm{min}^{-1}$ [100]. The profile of the flow rate was resolved by numerical simulations and the obtained information about the depletion zones was used for optimization of the electrode length [104]. Similar systems, based on diffusional components were also used by Palmore et al., who studied the influence of the diffusion layer thickness, alternative designs, number of electrodes and mass transport limitations on the cell current density, both experimentally and theoretically (the construction is presented in Figure 14A) [63,101]. Other reports of microfluidic biofuel cells employed immobilized enzymes and mediators in the presence of a soluble NADH $[20,60,105]$.

\subsection{Concentric biofuel cell}

Concentric biofuel cell was introduced by Tingry and co-workers [11,76]. The construction comprised two carbon tubular electrodes, placed in the same electrolyte, whereat the cathode tube was set up in the anode tube. Oxygen saturated solution was supplied to the inner of the cathode and diffused to its outer side, where it took part in the bioelectrochemical conversion (see Figure 14B). The promising compartmentalization approach allowed supply of dissolved oxygen separately from the electrolyte [76].

\subsection{Designs using MEA's}

Worth noting in the context of biofuel cell design is the implementation of enzyme electrodes in Nafion-based MEA's, which profit from the fact that the technology for MEA's preparation in the case of conventional fuel cells has been already established (see Figure 14C). The combination of a bioelectrode with a noble metal electrode, provided that the inorganic catalyst exhibits more stable behavior, allows focusing on the bioelectrode properties. Examples of several such systems, operating in liquid phase were already given throughout the review (e.g., the study by Fischback et al. addressed in the section discussing long-term stability testing [27]). However, there are reports in the literature, where gaseous operation of either the anode or the cathode has been reported. In some of the cases, fuel [16] or oxidant $[25,27,97]$ have been supplied in gas-phase to the Pt catalyst.

\subsection{Air-breathing cathodes}

The low solubility of oxygen in aqueous electrolytes was already addressed in the section discussing cathode kinetics. This limitation has motivated the employment of oxygen in gas-phase. For instance, there are reports of MEA-based systems, where the influence of gas humidification has been addressed [13,102]. Example of superior performance by utilization of gaseous oxygen has been given by Sakai et al. [32]. The authors constructed a passive type fuel cell with cellophane as separator, which exhibited current density of $14.1 \mathrm{~mA} \mathrm{~cm}^{-2}$ after 1 min polarization, while the current drawn in analogous experiment from a sink-type cell with dissolved oxygen decreased to almost zero [32]. 


\subsection{Modular stack cell}

The importance of defined geometry and dimensions of enzymatic biofuel cell devices has been outlined by Minteer et al. [1]. The difficulty in comparing and interpreting results from different laboratories has motivated the development of a modular stack cell as a standardized testing platform for enzymatic biofuel cells (see Figure 14D) [103]. The proposed stack cell design is flexible and can be used for various electrochemical experiments. This approach allows for better controlling of experimental conditions and other groups have also adopted similar design for fuel cells based on GDH/laccase [106] or FDH/laccase [43].

\section{Modeling of Enzymatic Biofuel Cells}

The use of modeling approach in order to understand and optimize the behavior of enzymatic fuel cells is not so common in the literature. Regarding modeling of complete fuel cell systems only few records can be found in literature [63,107-109]. Modeling of enzymatic electrodes is more studied, but mainly from the point of view of enzymatic biosensors ([110] and references therein). Electrodes for biosensors have significant overlap with enzymatic electrodes for fuel cell application but this aspect is already covered by the detailed review by Bartlett et al. [110]. In this review we will rather concentrate on those examples which refer to modeling of enzymatic electrodes for fuel cell applications.

\subsection{Complete fuel cell modeling}

Several approaches for enzymatic fuel cell modeling can be found in literature, e.g., classical material balancing including reaction kinetics and mass transport conditions [63,109], application of metabolic control analysis [107] or statistical analysis [108]. Unlike common fuel cell models [111] which are mainly used to predict current potential relationships or power curves under different operation conditions, enzymatic fuel cell models concentrate on modeling of e.g. fuel utilization [109], oxygen mass transport limitations [63] or optimum electrolyte composition [108] without presenting any polarization or power curve for the given conditions.

The models presented by Kjeang et al. [109] and Bedekar et al. [63] are numerical CFD models of microfluidic enzymatic fuel cells which include:

(a) Navier-Stokes equations for conservation of mass and momentum

$$
\begin{aligned}
& \nabla \vec{u}=0 \\
& \rho \frac{\partial \vec{u}}{\partial t}=\rho \vec{g}-\nabla p+\mu \nabla^{2} \vec{u}
\end{aligned}
$$

(b) the equation for mass conservation of solute species

$$
\begin{aligned}
& \frac{\partial c_{i}}{\partial t}=-\left(\nabla \vec{J}_{i}\right) \\
& \vec{J}_{i}=D_{i} \nabla c_{i}-\overrightarrow{u c_{i}}
\end{aligned}
$$


(c) and the equation for the current

$$
j=-\left.n F D \frac{d c_{\text {Mred }}}{d x}\right|_{x=0}
$$

In a theoretical work by Kjeang et al. [109] a concept of an enzymatic fuel cell, without presenting experimental system, was proofed. They tried to optimize the structure of a microfluidic enzymatic fuel cell, involving three-step-catalyzed methanol oxidation. Different enzyme patterning strategies were tested, e.g., spatially distributed- or evenly-mixed enzymes along the electrode surface. The model predicted high fuel utilization at low flow rates i.e., in the diffusion dominated and mixed mass, transfer conditions. According to the model, the investigated theoretical concept is reaction limited, which means that the system performance can be improved by improving enzyme turnover numbers. It was also calculated that the power required for pumping of the fuel is negligible in comparison to predicted power of the fuel cell [109].

The use of dissolved oxygen in enzymatic fuel cells is one of the main limitations of these systems due to low concentration and low diffusion coefficient of oxygen, which was discussed previously. Bedekar et al. investigated the influence of oxygen mass transport limitations on the performance of microfluidic enzymatic fuel cell [63]. An exponential decay in the availability of oxygen at the cathode was observed along the length of micro channel. Increase of the oxygen flow rate can reduce the oxygen mass transfer resistance, but disparity between flow rates of the anolyte and catholyte can induce wastage of dissolved oxygen [63].

Interesting approach for modeling enzymatic fuel cells was presented by Glykys et al. [107]. In a theoretical study they investigated an enzymatic fuel cell based on Os mediated glucose oxidase anode and laccase cathode. They varied oxygen concentration in the solution and concluded that it would not influence the GOx kinetics as long as the total mediator concentration is high. Another observation was that under the given conditions, the fuel cell performance would be dominated by the anode [107].

\subsection{Modeling of enzymatic electrodes}

Mathematical models of enzymatic electrodes in literature usually consider the enzymatic reaction and the material balance of species, which are taking place in the enzymatic reaction. In general, an enzymatic half-cell reaction can be represented as follows:

$$
S \stackrel{\text { enzyme }}{\longrightarrow} P+n H^{+}+n e^{-}
$$

The mechanism of this reaction depends on the type of electron transfer mechanism between the enzyme and the electrode. As it was discussed in previous sections DET or MET mechanism can be assumed. In the case of DET the mechanism of the reaction (1) can be presented as in [110]:

$$
\begin{aligned}
& E_{o x}+S \stackrel{K_{E S}}{\longrightarrow} E S \stackrel{k_{c a t}}{\longrightarrow} E_{r e d}+P \\
& E_{\text {red }} \rightarrow E_{o x}+n H^{+}+n e^{-}
\end{aligned}
$$

and in the case of MET as in [110,112-114]:

$$
\begin{aligned}
& E_{o x}+S \stackrel{K_{E S}}{\longrightarrow} E S \stackrel{k_{c a t}}{\longrightarrow} E_{r e d}+P \\
& E_{r e d}+M_{o x} \stackrel{K_{E M}}{\longrightarrow} E M \stackrel{k_{m}}{\longrightarrow} E_{o x}+M_{\text {red }}
\end{aligned}
$$




$$
M_{\text {red }} \rightarrow M_{o x}+n H^{+}+n e^{-}
$$

where $E_{\mathrm{ox}}, E_{\mathrm{red}}, E S, M_{\mathrm{ox}}, M_{\text {red }}$ and $E M$ are oxidized and reduced forms of enzyme, enzyme substrate complex, oxidized and reduced forms of mediator molecule and enzyme mediator complex, while $S$ and $P$ are substrate (reactant) and product of enzymatic reaction, respectively.

The DET mechanism (Equations 2-3) has a form of pure Michaelis-Menten kinetics, while the MET mechanism is an example of a so-called two-substrate ping-pong mechanism (Equations 4-6). First, the enzyme reacts with one substrate $(S)$, which changes the enzyme into its reduced form $\left(E_{\text {red }}\right)$. After that in a subsequent step $E_{\text {red }}$ reacts with mediator molecule and recovers its original state $\left(E_{\mathrm{ox}}\right)$.

For description of mass balance of species, which are taking place in the reactions (Equations 2-6) it is important to know the electrode configuration. In literature there is a number of possible enzymatic electrode configurations (as discussed in previous sections), e.g., mediator and enzyme are free diffusive, enzyme is immobilized and mediator can diffuse, both enzyme and mediator are immobilized or enzyme is directly oxidized on the electrode surface. For biofuel cell application interesting electrode configurations are those where enzymes are immobilized on the electrode surface. In these configurations enzyme can be directly oxidized on the electrode surface or it can be oxidized via immobilized or free diffusive mediator. So far in literature we could not find any report on DET modeling. Probably the reason is that only few enzymes exhibit DET and the majority of practical systems are based on MET. For this reason this review will concentrate on modeling of MET systems.

In the case of enzymatic electrodes, one deals with a heterogeneous process which means that the concentrations of species which are taking place in reactions (2) to (6) are functions of both time and space. In general for the species which can freely diffuse in and out of the catalyst layer (e.g., substrate or freely diffusive mediator molecule) the change of the concentration with time can be presented as follows:

$$
\frac{\partial c}{\partial t}=D \frac{\partial^{2} c(x, t)}{\partial x^{2}}+u_{x} \frac{\partial c(x, t)}{\partial x}-v_{e n z}
$$

where $D$ is diffusion coefficient for free diffusive species, $u_{\mathrm{x}}$ is velocity of convective flow and $v_{\text {enz }}$ is the rate of enzyme reaction. Equation (7) can be simplified by assuming ideal mixing in the bulk of the solution, by neglecting the influence of advection in the catalyst layer i.e., $u_{x} \frac{\partial c(x, t)}{\partial x} \approx 0$ and by assuming steady state conditions $\left(\frac{\partial c}{\partial t}=0\right)$ :

$$
D \frac{\partial^{2} c(x, t)}{\partial x^{2}}=v_{e n z}
$$

If the mediator molecule is not free diffusive, but immobilized on the surface (e.g., Os-based polymers, [114]) its material balance can be also described by Equation 8, but in this case diffusion coefficient $D$ corresponds to diffusion of charge through the matrix, rather than physical diffusion of mediator [115].

$v_{\text {enz }}$, the rate of enzyme reaction can be expressed as:

$$
v_{e n z}=\frac{k_{\text {over }} c_{\text {enz-tot }}}{1+\frac{K_{E S}}{c_{S}(x, t)}+\frac{K_{E M}}{c_{M o x}(x, t)}}
$$


where $c_{\text {enz_tot }}$ is total enzyme concentration including oxidized and reduced forms of enzyme and enzyme substrate complex, $k_{\mathrm{over}}$ is overall rate constant and $K_{\mathrm{ES}}$ and $K_{\mathrm{EM}}$ are constants for Reactions (2) and (5) respectively. Overall rate constant $k_{\text {over }}$ is defined as follows [114]:

$$
k_{\text {over }}=\frac{k_{c a t} k_{m}}{k_{c a t}+k_{m}}
$$

The current density $j$ is related to the flux of mediator reacting at the electrode $[110,113,114,116]$ :

$$
j=-\left.n F D \frac{d c_{M r e d}}{d x}\right|_{x=0}
$$

where $F$ stands for the Faraday's constant.

As already stated, in the case of free diffusive mediator, $D$ is its diffusion coefficient for diffusion in the catalyst layer, while in the case of immobilized mediator $D$ corresponds to diffusion of charge through the e.g. polymer matrix.

The enzyme electrode models published so far in literature have been used for determination of kinetic parameters. For instance, Galaway et al. used one-dimensional numeric model to obtain kinetic information $\left(k_{\mathrm{over}}, K_{\mathrm{ES}}, K_{\mathrm{EM}}\right)$ from cyclic voltammetry experiments for $\mathrm{O}_{2}$ reduction on laccase-based enzymatic electrodes modified by different Os redox hydrogels [114]. They found out that the rate constant for the reaction between laccase and oxygen was slightly lower than in free solution. It was also found out that the rate constant for the reaction between mediator and laccase depends linearly on mediator potential in the potential range between $c a$. 0.5 and $0.8 \mathrm{~V}$ while in the potential range between $c a$. 0.1 to $0.5 \mathrm{~V}$ it was independent on mediator potential.

In their theoretical paper, Tamaki et al. [113] modeled glucose oxidation on high surface area carbon black electrode in presence of GDH and redox polymer. They assumed different thicknesses of the catalyst layer and by changing diffusion coefficient of charge through the redox polymer, they obtained that the apparent electron diffusion in the polymer is not the rate determining step for overall electrode kinetics. According to their study current densities up to $0.1 \mathrm{~A} \mathrm{~cm}^{-2}$ could be obtained by using high surface area carbon black electrode in presence of redox polymer by increasing enzyme loading in the catalyst layer and enzyme turnover rate [113].

\section{Enzymatic Fuel Cells Optimization}

The limited power output and the insufficient long-term stability under continuous operation suggest further optimization of enzymatic biofuel cells. The improvement of performance requires optimization of all fuel cell components like biocatalysts, mediators, enzymatic electrode assemblies and fuel cell design. Most of these issues were already addressed in the text above. One aspect that was little covered is improvement of the biocatalyst. As it was already discussed the performance of enzymatic electrodes is very much dependent on the properties of the employed biocatalyst. It was shown that the properties of enzymes for fuel cell application can be improved by purification [92] or deglycosylation [94] in the case of GOx. Another powerful strategy, which allows that the properties of biocatalysts can be even more altered and theoretically finely tuned for target applications, is enzyme engineering.

There are two general approaches that are used in protein engineering, as outlined in a review by Schwaneberg et al. [117]. Rational design is used, when there is information or a hypothesis about the structure-activity relationship of the protein and a site-directed mutagenesis can be used to verify such 
assumptions. Example for that is MP-11, which represents the active site and the microenvironment around of cytochrome c, as discussed previously [37]. Directed evolution should be used, when there is no information about the structure and the associated activity and in this case potential candidates are identified by screening of different mutants [117]. Example for that is a study by the same group, where a GOx mutant with increased affinity for glucose $\left(K_{m}=20.7 \mathrm{mM}\right.$ versus $18.7 \mathrm{mM}$ for the wild type $)$ and reduced oxygen consumption $\left(K_{m}=474.2 \mu \mathrm{M}\right.$ versus $700.8 \mu \mathrm{M}$ for the wild type $)$ has been introduced [118].

There are several other studies in the literature, where protein engineering has been addressed for biofuel cells application. For instance, the surface charge and nucleophilicity of a lactate dehydrogenase have been varied by introduction of polyhistidine or cysteine residues in order to improve the immobilization in conductive polymers [119]. In another example pyranose 2-oxidase (EC 1.1.3.10) was subjected to semi-rational design and mutants with improved kinetics towards glucose and different mediators were identified [120].

Another enzyme extensively subjected to protein engineering is the PQQ-dependent GDH. The protein has higher activity towards glucose than GOx, it does not require a soluble co-factor as NADH and does not involve oxygen as an electron acceptor but the lower stability and substrate specificity have motivated efforts for genetic tuning of its properties, which were outlined in a minireview by Sode and co-workers [121]. The authors reported biofuel cell devices, utilizing engineered PQQ-GDH with improved stability [122] and a mutant, able of DET (quinohemoprotein-glucose dehydrogenase, QH-GDH) obtained from fusion of a cytochrome c domain with PQQ-GDH (see Figure 15) [21].

Figure 15. Construction of engineered enzyme (QH-GDH) by fusion of the cytochrome c domain of quinohemoprotein ethanol dehydrogenase (QH-EDH) to the $\mathrm{C}$ terminus of PQQ-dependent glucose dehydrogenase (PQQGDH). Reprinted from [121] with permission from Elsevier.

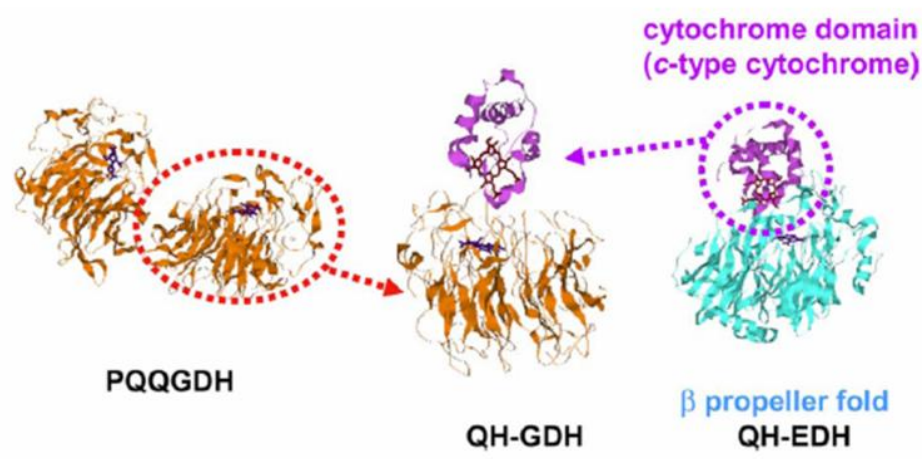

The same group cloned a novel, thermostable GDH consisting of three subunits (FAD-containing, heme c containing and a chaperone-like subunit). The protein was found to exhibit DET and the performance of the subunit and the GDH complex was evaluated in a biofuel cell [123] and a fuel-cell type biosensor [26].

The protein engineering approach has been applied to oxygen reducing proteins such as BOD, wherein DET was achieved through site-directed mutagenesis by substitution of methionine by glutamine in the T1 domain [124]. 


\section{Summary}

In the present review, we have summarized recent advances in experiments and modeling of enzymatic fuel cells. The typical fuel used in such systems is glucose and the typical oxidant is oxygen. Apart from glucose, other sugars and low aliphatic alcohols also have been employed as fuels in biofuel cells. Mostly used enzymes for glucose oxidation are GOx and GDH. Recently, a new enzyme, $\mathrm{CDH}$, has been introduced as a promising alternative. In comparison to GOx CDH profits from the broad spectrum of substrates, low oxygen sensitivity and ability of DET and unlike GDH does not require a soluble co-factor. The most widely employed enzymes for the cathode reaction are the multi-copper oxidases as laccase and BOD and both of them can exhibit DET.

Regarding the electrode assemblies, there is a variety of architectures but a clear trend can be seen in direction of three-dimensional matrices and nanostructured materials. In this context we would like to highlight the architectures based on CNT's, which can be used in absence of mediator and architectures based on Os polymers for both anode and cathode reactions. In general there are numerous combinations of enzymes and mediators that have been employed in biofuel cells but the respective studies typically involve monoenzymatic systems, which are capable of only partial oxidation of the fuel. Improvement of fuel utilization can be achieved by complete oxidation, which has been realized by introduction of enzyme cascades.

It has been shown that kinetics of bioelectrochemical reactions depends on various factors like type of enzyme and mediator, active surface area, $\mathrm{pH}$, type and concentration of substrate, composition of electrolyte, etc. In the case of MET-based systems, overall electrode kinetics is mainly dependent on mediator kinetics, so the major improvement in terms of voltage could be obtained by the choice of suitable mediator. In terms of currents improvement, the standard approach involves increasing of the active surface area, often achieved by use of nanostructured materials.

The typical enzymatic fuel cell demonstrates powers in the microwatt range and low long-term stability. Biofuel cell tests are often performed under quite different conditions (concentration, temperature, $\mathrm{pH}$, mass transport conditions, etc.), which complicates or hampers the comparison between different configurations. It is obvious that for straightforward characterization some standardization is needed and the logical way is adoption of methods from conventional fuel cells research. Regarding the electrochemical experiments we would like to underline the importance of steady-state measurements. Once an unambiguous characterization of the biofuel cell performance under steady-state conditions has been done, dynamic experiments for simulation of real applications can be performed. The definition of a steady-state for given system should be a compromise between its intrinsic properties and the inherent instability, associated mainly with the nature of employed biocatalysts.

Essential for the future application of enzymatic fuel cells is their long-term stability. However, such tests in the literature have been often neglected or conducted in inappropriate manner. The utilization of a batch container as the conventional electrochemical cell or a beaker raises the problems of substrate depletion and product accumulation. Flow-through systems offer possible solution for the long-term stability investigation of biofuel cells. In general there is a progress in the biofuel cell design, although most of the reported configurations are based on a simple batch type system with focus on the chemistry and processes occurring at the bioelectrode interface. More sophisticated designs have been 
introduced by the construction of microfluidic or other flow-through devices, as well as by the management of oxygen supply in air-breathing cells or cells with unusual design.

There are only few studies addressing modeling of enzymatic fuel cells and experimental validation of proposed models is even more seldom. More effort in the future is needed in this direction in order to understand and further optimize the biofuel cell performance. Enzymatic biofuel cells offer alternatives to conventional fuel cells and batteries for some specific applications and further optimization of the biofuel cell components will require joint efforts of groups from different disciplines.

\section{References:}

1. Cooney, M.J.; Svoboda, V.; Lau, C.; Martin, G.; Minteer, S.D. Enzyme catalysed biofuel cells. Energy Environ. Sci. 2008, 1, 320-337.

2. Minteer, S.D.; Liaw, B.Y.; Cooney, M.J. Enzyme-based biofuel cells. Curr. Opin. Biotechnol. 2007, 18, 228-234.

3. Kannan, A.M.; Renugopalakrishnan, V.; Filipek, S.; Li, P.; Audette, G.F.; Munukutla, L. Bio-Batteries and Bio-Fuel Cells: Leveraging on Electronic Charge Transfer Proteins. In International Conference on Bionano Science (ICONBS 2007), Taipei, Taiwan, December 2007; pp. $1665-1678$.

4. Cracknell, J.A.; Vincent, K.A.; Armstrong, F.A. Enzymes as working or inspirational electrocatalysts for fuel cells and electrolysis. Chem. Rev. 2008, 108, 2439-2461.

5. Heller, A. Miniature biofuel cells. Phys. Chem. Chem. Phys. 2004, 6, 209-216.

6. Willner, I.; Yan, Y.M.; Willner, B.; Tel-Vered, R. Integrated enzyme-based biofuel cells-A review. Fuel Cells 2009, 9, 7-24.

7. Zayats, M.; Willner, B.; Willner, I. Design of amperometric biosensors and biofuel cells by the reconstitution of electrically contacted enzyme electrodes. Electroanalysis 2008, 20, 583-601.

8. Barton, S.C.; Gallaway, J.; Atanassov, P. Enzymatic biofuel cells for Implantable and microscale devices. Chem. Rev. 2004, 104, 4867-4886.

9. Bullen, R.A.; Arnot, T.C.; Lakeman, J.B.; Walsh, F.C. Biofuel cells and their development. Biosens. Bioelectron. 2006, 21, 2015-2045.

10. Sakai, M.; Vonderheit, A.; Wei, X.; Kuttel, C.; Stemmer, A. A novel biofuel cell harvesting energy from activated human macrophages. Biosens. Bioelectron. 2009, 25, 68-75.

11. Habrioux, A.; Servat, K.; Tingry, S.; Kokoh, K.B. Enhancement of the performances of a single concentric glucose/O-2 biofuel cell by combination of bilirubin oxidase/nafion cathode and Au-Pt anode. Electrochem. Commun. 2009, 11, 111-113.

12. Zheng, W.; Zho, H.M.; Zheng, Y.F.; Wang, N. A comparative study on electrochemistry of laccase at two kinds of carbon nanotubes and its application for biofuel cell. Chem. Phys. Lett. 2008, 457, 381-385.

13. Smolander, M.; Boer, H.; Valkiainen, M.; Roozeman, R.; Bergelin, M.; Eriksson, J.E.; Zhang, X.C.; Koivula, A.; Viikari, L. Development of a printable laccase-based biocathode for fuel cell applications. In Proceedings of the 10th International Congress on Biotechnology in Pulp and Paper, Madison, WI, USA, June 2007; pp. 93-102. 
14. Habrioux, A.; Sibert, E.; Servat, K.; Vogel, W.; Kokoh, K.B.; Alonso-Vante, N. Activity of platinum-gold alloys for glucose electrooxidation in biofuel cells. J. Phys. Chem. B 2007, 111, 10329-10333.

15. Colmati, F.; Yoshioka, S.A.; Silva, V.; Varela, H.; Gonzalez, E.R. Enzymatic based biocathode in a polymer electrolyte membrane fuel cell. Int. J. Electrochem. Sci. 2007, 2, 195-202.

16. Hudak, N.S.; Barton, S.C. Mediated biocatalytic cathode for direct methanol membrane-electrode assemblies. J. Electrochem. Soc. 2005, 152, A876-A881.

17. Palmore, G.T.R.; Kim, H.H. Electro-enzymatic reduction of dioxygen to water in the cathode compartment of a biofuel cell. J. Electroanal. Chem. 1999, 464, 110-117.

18. Tasca, F.; Gorton, L.; Harreither, W.; Haltrich, D.; Ludwig, R.; Noll, G. Highly efficient and versatile anodes for biofuel cells based on cellobiose dehydrogenase from Myriococcum thermophilum. J. Phys. Chem. C 2008, 112, 13668-13673.

19. Muguruma, H. Biofuel cell based on a complex between glucose oxidase and a plasmapolymerized film containing a redox site. IEICE Trans. Electron. 2008, E91C, 1811-1815.

20. Togo, M.; Takamura, A.; Asai, T.; Kaji, H.; Nishizawa, M. An enzyme-based microfluidic biofuel cell using vitamin K-3-mediated glucose oxidation. Electrochim. Acta 2007, 52, 4669-4674.

21. Okuda, J.; Yamazaki, T.; Fukasawa, M.; Kakehi, N.; Sode, K. The application of engineered glucose dehydrogenase to a direct electron-transfer-type continuous glucose monitoring system and a compartmentless biofuel cell. Anal. Lett. 2007, 40, 431-440.

22. Kuwahara, T.; Oshima, K.; Shimomura, M.; Miyauchi, S. Properties of the enzyme electrode fabricated with a film of polythiophene derivative and its application to a glucose fuel cell. J. Appl. Polym. Sci. 2007, 104, 2947-2953.

23. Arechederra, R.L.; Treu, B.L.; Minteer, S.D. Development of glycerol/O-2 biofuel cell. J. Power Sources 2007, 173, 156-161.

24. Zhang, X.C.; Ranta, A.; Halme, A. Direct methanol biocatalytic fuel cell-Considerations of restraints on electron transfer. Biosens. Bioelectron. 2006, 21, 2052-2057.

25. Tamaki, T.; Yamaguchi, T. High-surface-area three-dimensional biofuel cell electrode using redox-polymer-grafted carbon. Ind. Eng. Chem. Res. 2006, 45, 3050-3058.

26. Kakehi, N.; Yamazaki, T.; Tsugawa, W.; Sode, K. A novel wireless glucose sensor employing direct electron transfer principle based enzyme fuel cell. In 9th World Congress on Biosensors, Toronto, Canada, May, 2006; pp. 2250-2255.

27. Fischback, M.B.; Youn, J.K.; Zhao, X.Y.; Wang, P.; Park, H.G.; Chang, H.N.; Kim, J.; Ha, S. Miniature biofuel cells with improved stability under continuous operation. Electroanalysis 2006, 18, 2016-2022.

28. Sato, F.; Togo, M.; Islam, M.K.; Matsue, T.; Kosuge, J.; Fukasaku, N.; Kurosawa, S.; Nishizawa, M. Enzyme-based glucose fuel cell using Vitamin K-3-immobilized polymer as an electron mediator. Electrochem. Commun. 2005, 7, 643-647.

29. Akers, N.L.; Moore, C.M.; Minteer, S.D. Development of alcohol/O-2 biofuel cells using saltextracted tetrabutylammonium bromide/Nafion membranes to immobilize dehydrogenase enzymes. Electrochim. Acta 2005, 50, 2521-2525. 
30. Palmore, G.T.R.; Bertschy, H.; Bergens, S.H.; Whitesides, G.M. A methanol/dioxygen biofuel cell that uses $\mathrm{NAD}(+)$-dependent dehydrogenases as catalysts: application of an electro-enzymatic method to regenerate nicotinamide adenine dinucleotide at low overpotentials. J. Electroanal. Chem. 1998, 443, 155-161.

31. Choi, Y.K.; Wang, G.; Nayfeh, M.H.; Yau, S.T. A hybrid biofuel cell based on electrooxidation of glucose using ultra-small silicon nanoparticles. Biosens. Bioelectron. 2009, 24, 3103-3107.

32. Sakai, H.; Nakagawa, T.; Tokita, Y.; Hatazawa, T.; Ikeda, T.; Tsujimura, S.; Kano, K. A high-power glucose/oxygen biofuel cell operating under quiescent conditions. Energy Environ. Sci. 2009, 2, 133-138.

33. Heller, A. Potentially implantable miniature batteries. In Proceedings of the Annual Meeting of the Gesellschaft-Deutscher-Chemiker, Regensburg, Germany, February 2005; pp. 469-473.

34. Heller, A. Integrated medical feedback systems for drug delivery. In Meeting on Lessening the Pain and Worry of Diabetic People held at the AICHE Annual Meeting, Austin, TX, USA, November 2004; pp. 1054-1066.

35. Ramirez, P.; Mano, N.; Andreu, R.; Ruzgas, T.; Heller, A.; Gorton, L.; Shleev, S. Direct electron transfer from graphite and functionalized gold electrodes to T1 and T2/T3 copper centers of bilirubin oxidase. Biochim. Biophys. Acta, Bioenerg. 2008, 1777, 1364-1369.

36. Shleev, S.; Jarosz-Wilkolazka, A.; Khalunina, A.; Morozova, O.; Yaropolov, A.; Ruzgas, T.; Gorton, L. Direct electron transfer reactions of laccases from different origins on carbon electrodes. Bioelectrochemistry 2005, 67, 115-124.

37. Willner, I.; Katz, E.; Patolsky, F.; Buckmann, A.F. Biofuel cell based on glucose oxidase and microperoxidase-11 monolayer-fundionalized electrodes. J. Chem. Soc., Perkin Trans. 1998, 2 , 1817-1822.

38. Katz, E.; Filanovsky, B.; Willner, I. A biofuel cell based on two immiscible solvents and glucose oxidase and microperoxidase-11 monolayer-functionalized electrodes. New J. Chem. 1999, 23, 481-487.

39. Wilson, R.; Turner, A.P.F. Glucose-oxidase - An ideal enzyme. Biosens. Bioelectron. 1992, 7 , 165-185.

40. Coman, V.; Vaz-Dominguez, C.; Ludwig, R.; Herreither, W.; Haltrich, D.; De Lacey, A.L.; Ruzgas, T.; Gorton, L.; Shleev, S. A membrane-, mediator-, cofactor-less glucose/oxygen biofuel cell. Phys. Chem. Chem. Phys. 2008, 10, 6093-6096.

41. Tsujimura, S.; Kano, K.; Ikeda, T. Glucose/O-2 biofuel cell operating at physiological conditions. Electrochemistry 2002, 70, 940-942.

42. Wu, X.; Zhao, F.; Varcoe, J.R.; Thumser, A.E.; Avignone-Rossa, C.; Slade, R.C.T. A onecompartment fructose/air biological fuel cell based on direct electron transfer. Biosens. Bioelectron. 2009, 25, 326-331.

43. Kamitaka, Y.; Tsujimura, S.; Setoyama, N.; Kajino, T.; Kano, K. Fructose/dioxygen biofuel cell based on direct electron transfer-type bioelectrocatalysis. Phys. Chem. Chem. Phys. 2007, 9, 1793-1801.

44. Sokic-Lazic, D.; Minteer, S.D. Citric acid cycle biomimic on a carbon electrode. Biosens. Bioelectron. 2008, 24, 939-944. 
45. Sokic-Lazic, D.; Minteer, S.D. Pyruvate/air enzymatic biofuel cell capable of complete oxidation. Electrochem. Solid-State Lett. 2009, 12, F26-F28.

46. Ramanavicius, A.; Kausaite, A.; Ramanaviciene, A. Enzymatic biofuel cell based on anode and cathode powered by ethanol. Biosens. Bioelectron. 2008, 24, 761-766.

47. Arechederra, R.L.; Minteer, S.D. Complete oxidation of glycerol in an enzymatic biofuel cell. Fuel Cells 2009, 9, 63-69.

48. Vincent, K.A.; Cracknell, J.A.; Lenz, O.; Zebger, I.; Friedrich, B.; Armstrong, F.A. Electrocatalytic hydrogen oxidation by an enzyme at high carbon monoxide or oxygen levels. Proc. Natl. Acad. Sci. U. S. A. 2005, 102, 16951-16954.

49. Katz, E.; Willner, I.; Kotlyar, A.B. A non-compartmentalized glucose vertical bar O-2 biofuel cell by bioengineered electrode surfaces. J. Electroanal. Chem. 1999, 479, 64-68.

50. Pizzariello, A.; Stred'ansky, M.; Miertus, S. A glucose/hydrogen peroxide biofuel cell that uses oxidase and peroxidase as catalysts by composite bulk-modified bioelectrodes based on a solid binding matrix. In Proceedings of the 16th International Symposium on Bioelectrochemistry and Bioenergetics, Bratislava, Slovakia, Jun 2001; pp. 99-105.

51. Ramanavicius, A.; Kausaite, A.; Ramanaviciene, A. Biofuel cell based on direct bioelectrocatalysis. In Proceedings of the 8th World Congress on Biosensors, Granada, Spain, May 2004; pp. 1962-1967.

52. Ramanavicius, A.; Ramanaviciene, A. Hemoproteins in design of biofuel cells. Fuel Cells 2009, 9 , $25-36$.

53. Habermuller, L.; Mosbach, M.; Schuhmann, W. Electron-transfer mechanisms in amperometric biosensors. Fresenius' J. Anal. Chem. 2000, 366, 560-568.

54. Zhao, H.Y.; Zhou, H.M.; Zhang, J.X.; Zheng, W.; Zheng, Y.F. Carbon nanotube-hydroxyapatite nanocomposite: A novel platform for glucose/O-2 biofuel cell. Biosens. Bioelectron. 2009, 25, 463-468.

55. Wang, S.C.; Yang, F.; Silva, M.; Zarow, A.; Wang, Y.B.; Iqbal, Z. Membrane-less and mediator-free enzymatic biofuel cell using carbon nanotube/porous silicon electrodes. Electrochem. Commun. 2009, 11, 34-37.

56. Li, X.C.; Zhou, H.J.; Yu, P.; Su, L.; Ohsaka, T.; Mao, L.Q. A miniature glucose/O-2 biofuel cell with single-walled carbon nanotubes-modified carbon fiber microelectrodes as the substrate. Electrochem. Commun. 2008, 10, 851-854.

57. Deng, L.; Shang, L.; Wang, Y.Z.; Wang, T.; Chen, H.J.; Dong, S.J. Multilayer structured carbon nanotubes/poly-L-lysine/laccase composite cathode for glucose/O-2 biofuel cell. Electrochem. Commun. 2008, 10, 1012-1015.

58. Yan, Y.M.; Su, L.; Mao, L.Q. Multi-walled carbon nanotube-based glucose/O-2 biofuel cell with glucose oxidase and laccase as biocatalysts. J. Nanosci. Nanotechnol. 2007, 7, 1625-1630.

59. Li, X.; Zhang, L.; Su, L.; Ohsaka, T.; Mao, L. A miniature glucose/O-2 biofuel cell with a high tolerance against ascorbic acid. Fuel Cells 2009, 9, 85-91.

60. Togo, M.; Takamura, A.; Asai, T.; Kaji, H.; Nishizawa, M. Structural studies of enzyme-based microfluidic biofuel cells. J. Power Sources 2008, 178, 53-58. 
61. Liu, Y.; Dong, S.J. A biofuel cell harvesting energy from glucose-air and fruit juice-air. Biosens. Bioelectron. 2007, 23, 593-597.

62. Gao, F.; Yan, Y.M.; Su, L.; Wang, L.; Mao, L.Q. An enzymatic glucose/O-2 biofuel cell: Preparation, characterization and performance in serum. Electrochem. Commun. 2007, 9, 989-996.

63. Bedekar, A.S.; Feng, J.J.; Krishnamoorthy, S.; Lim, K.G.; Palmore, G.T.R.; Sundaram, S. Oxygen limitation in microfluidic biofuel cells. Chem. Eng. Commun. 2008, 195, 256-266.

64. Brunel, L.; Denele, J.; Servat, K.; Kokoh, K.B.; Jolivalt, C.; Innocent, C.; Cretin, M.; Rolland, M.; Tingry, S. Oxygen transport through laccase biocathodes for a membrane-less glucose/O-2 biofuel cell. Electrochem. Commun. 2007, 9, 331-336.

65. Nazaruk, E.; Smolinski, S.; Swatko-Ossor, M.; Ginalska, G.; Fiedurek, J.; Rogalski, J.; Bilewicz, R. Enzymatic biofuel cell based on electrodes modified with lipid liquid-crystalline cubic phases. J. Power Sources 2008, 183, 533-538.

66. Yan, Y.M.; Zheng, W.; Su, L.; Mao, L.Q. Carbon-nanotube-based glucose/O-2 biofuel cells. Adv. Mater. 2006, 18, 2639.

67. Zhou, M.; Deng, L.; Wen, D.; Shang, L.; Jin, L.H.; Dong, S.J. Highly ordered mesoporous carbons-based glucose/O-2 biofuel cell. Biosens. Bioelectron. 2009, 24, 2904-2908.

68. Yan, Y.M.; Yehezkeli, O.; Willner, I. Integrated, electrically contacted NAD(P)(+)-dependent enzyme - carbon nanotube electrodes for biosensors and biofuel cell applications. Chem.- Eur. J. 2007, 13, 10168-10175.

69. Topcagic, S.; Minteer, S.D. Development of a membraneless ethanol/oxygen biofuel cell. In Proceedings of the International Conference on Electrode Processes, Szczyrk, Poland, September 2004; pp. 2168-2172.

70. Liu, Y.; Wang, M.K.; Zhao, F.; Liu, B.F.; Dong, S.J. A low-cost biofuel cell with pH-dependent power output based on porous carbon as matrix. Chem. Eur. J. 2005, 11, 4970-4974.

71. Liu, Y.; Dong, S.J. A biofuel cell with enhanced power output by grape juice. Electrochem. Commun. 2007, 9, 1423-1427.

72. Tan, Y.M.; Deng, W.F.; Ge, B.; Xie, Q.J.; Huang, J.H.; Yao, S.Z. Biofuel cell and phenolic biosensor based on acid-resistant laccase-glutaraldehyde functionalized chitosan-multiwalled carbon nanotubes nanocomposite film. Biosens. Bioelectron. 2009, 24, 2225-2231.

73. Merle, G.; Habrioux, A.; Servat, K.; Rolland, M.; Innocent, C.; Kokoh, K.B.; Tingry, S. Long-term activity of covalent grafted biocatalysts during intermittent use of a glucose/O-2 biofuel cell. Electrochim. Acta 2009, 54, 2998-3003.

74. Kim, J.; Kim, S.I.; Yoo, K.H. Polypyrrole nanowire-based enzymatic biofuel cells. Biosens. Bioelectron. 2009, 25, 350-355.

75. Komaba, S.; Mitsuhashi, T.; Shraishi, S. Optimization of enzyme anode and cathode with polyion complex for the application to biofuel cells. Electrochemistry 2008, 76, 619-624.

76. Habrioux, A.; Merle, G.; Servat, K.; Kokoh, K.B.; Innocent, C.; Cretin, M.; Tingry, S. Concentric glucose/O-2 biofuel cell. J. Electroanal. Chem. 2008, 622, 97-102.

77. Ivanov, I.; Vidakovic, T.R.; Sundmacher, K. Glucose electrooxidation for biofuel cell applications. Chem. Biochem. Eng. 2009, 23, 77-86. 
78. Tan, Y.M.; Xie, Q.J.; Huang, J.H.; Duan, W.S.; Ma, M.; Yao, S.Z. Study on glucose biofuel cells using an electrochemical noise device. Electroanalysis 2008, 20, 1599-1606.

79. Soukharev, V.; Mano, N.; Heller, A. A four-electron O-2-electroreduction biocatalyst superior to platinum and a biofuel cell operating at 0.88 V. J. Am. Chem. Soc. 2004, 126, 8368-8369.

80. Mano, N.; Mao, F.; Shin, W.; Chen, T.; Heller, A. A miniature biofuel cell operating at 0.78 V. Chem. Commun. 2003, 518-519.

81. Chen, T.; Barton, S.C.; Binyamin, G.; Gao, Z.Q.; Zhang, Y.C.; Kim, H.H.; Heller, A. A miniature biofuel cell. J. Am. Chem. Soc. 2001, 123, 8630-8631.

82. Mano, N.; Mao, F.; Heller, A. A miniature membrane-less biofuel cell operating at $+0.60 \mathrm{~V}$ under physiological conditions. ChemBioChem 2004, 5, 1703-1705.

83. Mano, N.; Mao, F.; Heller, A. Characteristics of a miniature compartment-less glucose-O-2 biofuel cell and its operation in a living plant. J. Am. Chem. Soc. 2003, 125, 6588-6594.

84. Mano, N.; Heller, A. A miniature membraneless biofuel cell operating at $0.36 \mathrm{~V}$ under physiological conditions. J. Electrochem. Soc. 2003, 150, A1136-A1138.

85. Kim, H.H.; Mano, N.; Zhang, X.C.; Heller, A. A miniature membrane-less biofuel cell operating under physiological conditions at 0.5 V. J. Electrochem. Soc. 2003, 150, A209-A213.

86. Mano, N.; Mao, F.; Heller, A. A miniature biofuel cell operating in a physiological buffer. J. Am. Chem. Soc. 2002, 124, 12962-12963.

87. Barriere, F.; Kavanagh, P.; Leech, D. A laccase-glucose oxidase biofuel cell prototype operating in a physiological buffer. In Proceedings of 18th International Symposium on Bioelectrochemistry and Bioenergetics/3rd Spring Meeting of the International-Society-of-Electrochemistry, Coimbra, Portugal, Jun 2005; pp. 5187-5192.

88. Stoica, L.; Dimcheva, N.; Ackermann, Y.; Karnicka, K.; Guschin, D.A.; Kulesza, P.J.; Rogalski, J.; Haltrich, D.; Ludwig, R.; Gorton, L.; Schuhmann, W. Membrane-less biofuel cell based on cellobiose dehydrogenase (anode)/laccase (cathode) wired via specific os-redox polymers. Fuel Cells 2009, 9, 53-62.

89. Barriere, F.; Ferry, Y.; Rochefort, D.; Leech, D. Targetting redox polymers as mediators for laccase oxygen reduction in a membrane-less biofuel cell. Electrochem. Commun. 2004, 6, 237-241.

90. Zafar, M.N.; Tasca, F.; Gorton, L.; Patridge, E.V.; Ferry, J.G.; Noll, G. Tryptophan RepressorBinding Proteins from Escherichia coli and Archaeoglobus fulgidus as New Catalysts for 1,4-Dihydronicotinamide Adenine Dinucleotide-Dependent Amperometric Biosensors and Biofuel Cells. Anal. Chem. 2009, 81, 4082-4088.

91. Heller, A. Electron-conducting redox hydrogels: design, characteristics and synthesis. Curr. Opin. Chem. Biol. 2006, 10, 664-672.

92. Gao, F.; Courjean, O.; Mano, N. An improved glucose/O-2 membrane-less biofuel cell through glucose oxidase purification. Biosens. Bioelectron. 2009, 25, 356-361.

93. Mano, N. A $280 \mu \mathrm{W} \mathrm{cm}$ ch $^{-2}$ biofuel cell operating at low glucose concentration. Chem. Commun. 2008, 2221-2223.

94. Courjean, O.; Gao, F.; Mano, N. Deglycosylation of glucose oxidase for direct and efficient glucose electrooxidation on a glassy carbon electrode. Angew. Chem., Int. Ed. 2009, 48, 5897-5899. 
95. Kim, J.; Parkey, J.; Rhodes, C.; Gonzalez-Martin, A. Development of a biofuel cell using glucose-oxidase- and bilirubin-oxidase-based electrodes. In Proceedings of the 213th Electrochemistry-Society Meeting 2008, Phoenix, AZ, USA, May 18, 2008; pp. 1043-1050.

96. Mano, N.; Fernandez, J.L.; Kim, Y.; Shin, W.; Bard, A.J.; Heller, A. Oxygen is electroreduced to water on a "wired" enzyme electrode at a lesser overpotential than on platinum. J. Am. Chem. Soc. 2003, 125, 15290-15291.

97. Ivanov, I.; Vidaković, T.; Sundmacher, K. A flow-through glucose-oxygen fuel cell based on enzymatic anode and Pt cathode. In Proceedings of the 60th Annual Meeting of the ISE, Beijing, China, August 2009.

98. Arechederra, R.; Minteer, S.D. Organelle-based biofuel cells: Immobilized mitochondria on carbon paper electrodes. In Proceedings of 58th Annual Meeting of the ISE, Banff, Canada, September 2007; pp. 6698-6703.

99. Tsujimura, S.; Fujita, M.; Tatsumi, H.; Kano, K.; Ikeda, T. Bioelectrocatalysis-based dihydrogen/dioxygen fuel cell operating at physiological pH. Phys. Chem. Chem. Phys. 2001, 3, 1331-1335.

100. Zebda, A.; Renaud, J.; Cretin, M.; Pichot, F.; Innocent, C.; Ferrigno, R.; Tingry, S. A microfluidic glucose biofuel cell to generate micropower from enzymes at ambient temperature. Electrochem. Commun. 2009, 11, 592-595.

101. Lim, K.G.; Palmore, G.T.R. Microfluidic biofuel cells: The influence of electrode diffusion layer on performance. Biosens. Bioelectron. 2007, 22, 941-947.

102. Hudak, N.S.; Gallaway, J.W.; Barton, S.C. Mediated biocatalytic cathodes operating on gas-phase air and oxygen in fuel cells. J. Electrochem. Soc. 2009, 156, B9-B15.

103. Svoboda, V.; Cooney, M.; Liaw, B.Y.; Minteer, S.; Piles, E.; Lehnert, D.; Barton, S.C.; Rincon, R.; Atanassov, P. Standardized characterization of electrocatalytic electrodes. Electroanalysis 2008, 20, 1099-1109.

104. Zebda, A.; Renaud, L.; Cretin, M.; Innocent, C.; Pichot, F.; Ferrigno, R.; Tingry, S. Electrochemical performance of a glucose/oxygen microfluidic biofuel cell. J. Power Sources 2009, 193, 602-606.

105. Moore, C.M.; Minteer, S.D.; Martin, R.S. Microchip-based ethanol/oxygen biofuel cell. Lab. Chip 2005, 5, 218-225.

106. Deng, L.; Wang, F.; Chen, H.J.; Shang, L.; Wang, L.; Wang, T.; Dong, S.J. A biofuel cell with enhanced performance by multilayer biocatalyst immobilized on highly ordered macroporous electrode. Biosens. Bioelectron. 2008, 24, 329-333.

107. Glykys, D.J.; Banta, S. Metabolic control analysis of an enzymatic biofuel cell. Biotechnol. Bioeng. 2009, 102, 1624-1635.

108. Jeon, S.W.; Lee, J.Y.; Lee, J.H.; Kang, S.W.; Park, C.H.; Kim, S.W. Optimization of cell conditions for enzymatic fuel cell using statistical analysis. J. Ind. Eng. Chem. 2008, 14, 338-343.

109. Kjeang, E.; Sinton, D.; Harrington, D.A. Strategic enzyme patterning for microfluidic biofuel cells. J. Power Sources 2006, 158, 1-12.

110. Bartlett, P.N.; Toh, C.S.; Calvo, E.J.; Flexer, V. Modelling biosensor responses. In Bioelectrochemistry : Fundamentals, Experimental Techniques and Applications; Bartlett, P.N., Ed.; Wiley: Chichester, England, 2008; pp. 267-325. 
111. Weber, A.Z.; Newman, J. Modeling transport in polymer-electrolyte fuel cells. Chem. Rev. 2004, 104, 4679-4726.

112. Kano, K.; Ikeda, T. Fundamentals and practices of mediated bioelectrocatalysis. Anal. Sci. 2000, $16,1013-1021$.

113. Tamaki, T.; Ito, T.; Yamaguchi, T. Modelling of reaction and diffusion processes in a high-surface-area biofuel cell electrode made of redox polymer-grafted carbon. Fuel Cells 2009, 9, 37-43.

114. Gallaway, J.W.; Barton, S.A.C. Kinetics of redox polymer-mediated enzyme electrodes. J. Am. Chem. Soc. 2008, 130, 8527-8536.

115. Bartlett, P.N.; Pratt, K.F.E. Theoretical treatment of diffusion and kinetics in amperometric immobilized enzyme electrodes. 1. Redox mediator entrapped within the film. J. Electroanal. Chem. 1995, 397, 61-78.

116. Matsumoto, R.; Kano, K.; Ikeda, T. Theory of steady-state catalytic current of mediated bioelectrocatalysis. J. Electroanal. Chem. 2002, 535, 37-40.

117. Wong, T.S.; Schwaneberg, U. Protein engineering in bioelectrocatalysis. Curr. Opin. Biotechnol. 2003, 14, 590-596.

118. Zhu, Z.W.; Momeu, C.; Zakhartsev, M.; Schwaneberg, U. Making glucose oxidase fit for biofuel cell applications by directed protein evolution. Biosens. Bioelectron. 2006, 21, 2046-2051.

119. Halliwell, C.M.; Simon, E.; Toh, C.S.; Cass, A.E.G.; Bartlett, P.N. The design of dehydrogenase enzymes for use in a biofuel cell: the role of genetically introduced peptide tags in enzyme immobilization on electrodes. In Proceedings of the 16th International Symposium on Bioelectrochemistry and Bioenergetics, Bratislava, Slovakia, June 2001; pp. 21-23.

120. Spadiut, O.; Pisanelli, I.; Maischberger, T.; Peterbauer, C.; Gorton, L.; Chaiyen, P.; Haltrich, D. Engineering of pyranose 2-oxidase: Improvement for biofuel cell and food applications through semi-rational protein design. J. Biotechnol. 2009, 139, 250-257.

121. Igarashi, S.; Okuda, J.; Ikebukuro, K.; Sode, K. Molecular engineering of PQQGDH and its applications. Arch. Biochem. Biophys. 2004, 428, 52-63.

122. Yuhashi, N.; Tomiyama, M.; Okuda, J.; Igarashi, S.; Ikebukuro, K.; Sode, K. Development of a novel glucose enzyme fuel cell system employing protein engineered PQQ glucose dehydrogenase. In Proceedings of the 8th World Congress on Biosensors, Granada, Spain, May 2004; pp. 2145-2150.

123. Okuda-Shimazaki, J.; Kakehi, N.; Yamazaki, T.; Tomiyama, M.; Sode, K. Biofuel cell system employing thermostable glucose dehydrogenase. Biotechnol. Lett. 2008, 30, 1753-1758.

124. Kamitaka, Y.; Tsujimura, S.; Kataoka, K.; Sakurai, T.; Ikeda, T.; Kano, K. Effects of axial ligand mutation of the type I copper site in bilirubin oxidase on direct electron transfer-type bioelectrocatalytic reduction of dioxygen. J. Electroanal. Chem. 2007, 601, 119-124.

(C) 2010 by the authors; licensee MDPI, Basel, Switzerland. This article is an open-access article distributed under the terms and conditions of the Creative Commons Attribution license (http://creativecommons.org/licenses/by/3.0/). 